\title{
Carnosic Acid, a Natural Diterpene, Attenuates Arsenic-Induced Hepatotoxicity via Reducing Oxidative Stress, MAPK Activation, and Apoptotic Cell Death Pathway
}

\author{
Sonjit Das, ${ }^{1}$ Swarnalata Joardar, ${ }^{1}$ Prasenjit Manna $\left(\mathbb{D},{ }^{2}\right.$ Tarun K. Dua, ${ }^{1}$ Niloy Bhattacharjee, \\ Ritu Khanra, ${ }^{1}$ Shovonlal Bhowmick $\left({ }^{3},{ }^{3}\right.$ Jatin Kalita, ${ }^{2}$ Achintya Saha, ${ }^{3}$ Supratim Ray, ${ }^{4}$ \\ Vincenzo De Feo $\left({ }^{\circ},{ }^{5}\right.$ and Saikat Dewanjee $\left(\mathbb{C}^{1}\right.$ \\ ${ }^{1}$ Advanced Pharmacognosy Research Laboratory, Department of Pharmaceutical Technology, Jadavpur University, \\ Kolkata 700032, India \\ ${ }^{2}$ Biological Science and Technology Division, CSIR-North East Institute of Science and Technology, Jorhat, Assam 785006, India \\ ${ }^{3}$ Department of Chemical Technology, University of Calcutta, Kolkata 700009, India \\ ${ }^{4}$ Department of Pharmaceutical Sciences, Assam University, Silchar 788011, India \\ ${ }^{5}$ Department of Pharmacy, University of Salerno, Fisciano 84084, Italy
}

Correspondence should be addressed to Vincenzo De Feo; defeo@unisa.it and Saikat Dewanjee; s.dewanjee@yahoo.com

Received 4 October 2017; Revised 19 December 2017; Accepted 14 March 2018; Published 2 May 2018

Academic Editor: Maria F. H. Carneiro

Copyright (c) 2018 Sonjit Das et al. This is an open access article distributed under the Creative Commons Attribution License, which permits unrestricted use, distribution, and reproduction in any medium, provided the original work is properly cited.

The present studies have been executed to explore the protective mechanism of carnosic acid (CA) against $\mathrm{NaAsO}_{2}$-induced hepatic injury. CA exhibited a concentration dependent $(1-4 \mu \mathrm{M})$ increase in cell viability against $\mathrm{NaAsO}_{2}(12 \mu \mathrm{M})$ in murine hepatocytes. $\mathrm{NaAsO}_{2}$ treatment significantly enhanced the ROS-mediated oxidative stress in the hepatic cells both in in vitro and in vivo systems. Significant activation of MAPK, NF- $\kappa \mathrm{B}, \mathrm{p} 53$, and intrinsic and extrinsic apoptotic signaling was observed in $\mathrm{NaAsO}_{2}$-exposed hepatic cells. CA could significantly counteract with redox stress and ROS-mediated signaling and thereby attenuated $\mathrm{NaAsO}_{2}-$ mediated hepatotoxicity. $\mathrm{NaAsO}_{2}(10 \mathrm{mg} / \mathrm{kg})$ treatment caused significant increment in the As bioaccumulation, cytosolic ATP level, DNA fragmentation, and oxidation in the liver of experimental mice $(n=6)$. The serum biochemical and haematological parameters were significantly altered in the $\mathrm{NaAsO}_{2}$-exposed mice $(n=6)$. Simultaneous treatment with CA $(10 \mathrm{and} 20 \mathrm{mg} / \mathrm{kg})$ could significantly reinstate the $\mathrm{NaAsO}_{2}$-mediated toxicological effects in the liver. Molecular docking and dynamics predicted the possible interaction patterns and the stability of interactions between CA and signal proteins. ADME prediction anticipated the drug-likeness characteristics of CA. Hence, there would be an option to employ CA as a new therapeutic agent against As-mediated toxic manifestations in future.

\section{Introduction}

Arsenic (As) is a toxic metalloid, which raises much disquiet in the health standpoints for human and animals [1]. The primary natural pools of As are rocks, from which As is mobilized through natural different processes [2]. Besides the natural sources, industrial outcomes can also cause the release and mobilization of As to soil, water, and air in various forms $[2,3]$. Organic As compounds are not the concern for health risks [4]. Inorganic trivalent arsenicals (arsenites, $\mathrm{AsO}_{2}{ }^{-}$) are most potent toxicants [5]. Drinking water contaminated with arsenites is thought to be the major root of As calamity affecting $>140$ million people in $\sim 70$ countries [4]. Following ingestion, As is absorbed through the gastrointestinal tract and bioaccumulated into various organs [6]. It can also enter into the body through the respiratory system and dermis [7]. Intake of arsenites $>30 \mu \mathrm{g}$ per day has been reported to exert arsenicosis to the critical organs $[4,6,8]$. Earlier investigations revealed that As reduces mitochondrial integrity, resulting in random formation of superoxide radical which subsequently potentiates a cascade of radical reactions and enhances the secondary generation of other 


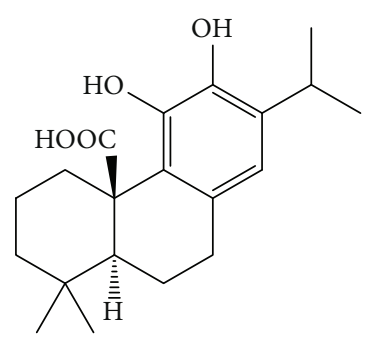

FIGURE 1: Structure of carnosic acid.

ROS $[6,7,9,10]$. On the other hand, As further promotes oxidative stress by reacting with -SH group and thereby deactivates the defense mechanism of several antioxidant enzymes and glutathione system [5]. The excess of ROS triggers wide ranges of pathological occurrences including damages to the structural components of cells, alteration in the expressions of genes, DNA damage, and apoptosis $[6,7]$. Despite As is a major threat to the global health, the development of a suitable therapy is still underway. The primary therapeutic strategy includes the treatment with chelating agents; however, the adverse effects like removal of essential metals and redistribution of As largely restricted their clinical usefulness [6]. The biological half-life of inorganic As is $\sim 10 \mathrm{~h}$ [11], which also argues against the employment of chelating agent as therapeutic negotiator. As-mediated augmented oxidative stress has been considered to be the principle etiology of arsenicosis. Therefore, it would be worthy to exploit the role of natural antioxidants to counteract As-mediated toxic manifestations.

Carnosic acid (CA), (4aR,10aS)-5,6-dihydroxy-1,1dimethyl-7-propan-2-yl-2,3,4,9,10,10a-hexahydrophenanthrene-4a-carboxylic acid, is a naturally occurring phenolic diterpene (Figure 1). CA is commonly found in Rosmarinus officinalis and Salvia officinalis $[12,13]$. CA has been reported to possess antioxidant $[14,15]$, neuroprotective [16], antiobesity [17], and anti-inflammatory [18] activities. Considering the antioxidant and radical scavenging effects of CA, the present studies have been undertaken to evaluate the possible therapeutic role of CA against As-induced hepatotoxicity.

\section{Material and Methods}

2.1. Chemicals. CA, bovine serum albumin (BSA), Dulbecco's modified Eagle's medium (DMEM), fetal bovine serum (FBS), Bradford reagent, and collagenase type I were procured from Sigma-Aldrich Chemical Company, MO, USA. Antibodies for immunoblotting were bought from Novus Biologicals, CO, USA. The solvents (HPLC grade) were obtained from Merck, Mumbai, India. Kits for the measurement of different biochemical parameters were procured from Span Diagnostics Ltd., India. 1-Chloro-2,4-dinitrobenzene, $\left(\mathrm{NH}_{4}\right)_{2} \mathrm{SO}_{4}, \mathrm{NaAsO}_{2}$, 2,4-dinitrophenylhydrazine, ethylenediaminetetraacetic acid, 5,5-dithiobis(2-nitrobenzoic acid), N-Ethylmaleimide, nitro blue tetrazolium, $\mathrm{NADH}$, $\mathrm{KH}_{2} \mathrm{PO}_{4}$, phenazine methosulphate, $\mathrm{Na}_{4} \mathrm{P}_{2} \mathrm{O}_{7}, \mathrm{GSH}, \mathrm{NaN}_{3}$, thiobarbituric acid, 5-thio-2-nitrobenzoic acid, and $\mathrm{CCl}_{3}$ $\mathrm{COOH}$ were obtained from Sisco Research Laboratory, Mumbai, India.
2.2. Animals. Healthy Swiss albino mice ( $0, \sim 2$ month old, $25 \pm 5 \mathrm{~g}$ ) were procured from Chakraborty Enterprise, Kolkata, India and were housed in standard polypropylene cages $(29 \times 22 \times 14 \mathrm{~cm})$ in the animal house of the Department of Pharmaceutical Technology, Jadavpur University, India. The mice were maintained with temperature $\left(22 \pm 2^{\circ} \mathrm{C}\right)$, humidity $(40 \pm 10 \%)$, and $12 \mathrm{~h}$ light-dark cycle [19]. The mice were fed standard diet and water ad libitum. The in vivo experiment has been permitted (Ref number AEC/PHARM/1701/ 09/2017) by the animal ethical committee, Jadavpur University (Reg. number: 0367/01/C/CPCSEA, UGC, India), and the principles of laboratory animal care were followed during the experiment [20]. The animals were acclimatized for a period of 2 weeks before the execution of the in vivo experiment.

\subsection{In Vitro Assays}

2.3.1. Determination of Cytotoxic Effect of $\mathrm{NaAsO}_{2}$. Hepatocytes were isolated from the liver of immediately sacrificed albino mice by two-step in situ collagenase perfusion as described by Dua et al. [6]. The hepatocytes were passaged at least a couple of times before the execution of in vitro experiment. Concentration-dependent cytotoxic effect of $\mathrm{NaAsO}_{2}$ was determined. Briefly, hepatocytes $\left(\sim 2 \times 10^{6}\right.$ cells/well $)$ were seeded in tissue culture plate and incubated at $37^{\circ} \mathrm{C}$ and $5 \% \mathrm{CO}_{2}$ for $24 \mathrm{~h}$ to form uniform monolayer of hepatocytes in the wells of culture plate. The cells were exposed to different concentrations of $\mathrm{NaAsO}_{2}$ for $2 \mathrm{~h}$, and the cell viability was determined employing MTT (3-(4,5-dimethylthiazolyl-2)-2, 5-diphenyltetrazolium bromide) assay [6]. The experiments were performed in triplicate. $\mathrm{NaAsO}_{2}$ exhibited $\mathrm{IC}_{50}$ value of $\sim 12 \mu \mathrm{M}$ in murine hepatocytes.

2.3.2. Determination of Effect of CA on Murine Hepatocytes. To determine the effect of CA on hepatocytes, hepatocytes $\left(\sim 2 \times 10^{6}\right.$ cells/set) were exposed to CA $(1,2,4,6$, and $10 \mu \mathrm{M})$. The experiments were performed in triplicate. The cell viability was measured employing MTT assay at different intervals up to $4 \mathrm{~h}[6]$.

2.3.3. Assessment of Cytoprotective Role of CA. To determine the cytoprotective effect of CA, hepatocytes $\left(\sim 2 \times 10^{6}\right.$ cells/ set) were exposed to $\mathrm{NaAsO}_{2}(12 \mu \mathrm{M})$ along with CA $(1,2,4,6$ and $10 \mu \mathrm{M})$. The experiments were performed in triplicate. The cell viability was measured employing MTT assay at different intervals up to $4 \mathrm{~h}$ [6]. One set of hepatocytes exposed to $\mathrm{NaAsO}_{2}(12 \mu \mathrm{M})$ was kept as toxic control, while an untreated set of hepatocytes was maintained as untreated control.

2.3.4. Hoechst Staining. Hoechst 33258 nuclear staining has been executed to study the cytotoxic events [21]. Briefly, hepatocytes $(\sim 2000$ cells/well $)$ were exposed to $\mathrm{NaAsO}_{2}$ $(12 \mu \mathrm{M})$ and $\mathrm{NaAsO}_{2}(12 \mu \mathrm{M})$ along with CA $(4 \mu \mathrm{M})$ for $2 \mathrm{~h}$ at $37^{\circ} \mathrm{C}$ and $5 \% \mathrm{CO}_{2}$. One set of hepatocytes without any treatment was kept as normal control. After $4 \mathrm{~h}$, hepatocytes were fixed with paraformaldehyde $(4 \%)$ in phosphate buffer saline (PBS) of pH 7.4 for $20 \mathrm{~min}$. The fixed hepatocytes were exposed to Hoechst $33258(5 \mu \mathrm{g} / \mathrm{ml}$ in PBS) for 
15 min followed by washing with PBS. Fluorescent nuclei and nuclear pattern were recorded. The experiments were performed in triplicate.

2.3.5. Flow Cytometric Analysis. The flow cytometric study has been performed to accomplish the nature of cell death. Briefly, hepatocytes were exposed to $\mathrm{NaAsO}_{2}(12 \mu \mathrm{M})$ and $\mathrm{NaAsO}_{2}(12 \mu \mathrm{M})$ along with CA $(4 \mu \mathrm{M})$ for $2 \mathrm{~h}$ at $37^{\circ} \mathrm{C}$ and $5 \% \mathrm{CO}_{2}$. One set of hepatocytes without any treatment was kept as normal control. After $2 \mathrm{~h}$, different sets of hepatocytes were treated with propidium iodide (PI) and FITC-labeled annexin $\mathrm{V}$ for $30 \mathrm{~min}$ at $37^{\circ} \mathrm{C}$ [21]. The excess of PI and annexin $\mathrm{V}$ was washed out, and the cells were fixed for analyzing in a flow cytometer using FACSCalibur (Becton Dickinson, Mountain View, USA) equipped with $488 \mathrm{~nm}$ argon laser light source; $515 \mathrm{~nm}$ band pass filter for FITC fluorescence and $623 \mathrm{~nm}$ band pass filter for PI fluorescence using CellQuest software, USA. The scatter plots of PI fluorescence ( $y$-axis) versus FITC fluorescence ( $x$-axis) were prepared for different sets of hepatocytes. The experiments were performed in triplicate.

2.3.6. Assays for Redox Markers. Different sets of hepatocytes, each containing $1 \mathrm{ml}$ of suspension $\left(\sim 2 \times 10^{6}\right.$ cells $\left./ \mathrm{ml}\right)$, were used in experiments. The prophylactic role of CA against $\mathrm{NaAsO}_{2}$ intoxication was analyzed by incubating hepatocytes with CA $(4 \mu \mathrm{M})$ and $\mathrm{NaAsO}_{2}(12 \mu \mathrm{M})$ together for $2 \mathrm{~h}$ at $37^{\circ} \mathrm{C}$. One set of hepatocytes incubated with $\mathrm{NaAsO}_{2}$ $(12 \mu \mathrm{M})$ served as toxic control. One set of hepatocytes without any treatment was kept as normal control. The intracellular ROS production was estimated by measuring the fluorescence of 2,7-dichlorofluorescein diacetate (DCF) in a fluorescence spectrometer (Olympus 1X70, Japan) following the method as described by Manna and Jain [22]. The levels of lipid peroxidation, protein carbonylation, reduced glutathione (GSH), and the levels of endogenous antioxidant enzymes, namely superoxide dismutase (SOD), catalase (CAT), glutathione peroxidase (GPx), glutathione-S-transferase (GST), and glutathione reductase (GR), were quantified employing reputable protocols [23]. The experiments were performed in triplicate.

2.3.7. Western Blotting of Signal Proteins in the Hepatocytes. The protein samples of hepatocytes for specific cellular components namely whole cell, cytosolic, and mitochondrial fractions were separated following standard sequential fractionation procedure as described by Baghirova and coworkers [24]. The sample proteins $(20 \mu \mathrm{g})$ were resolved in $12 \%$ SDS-PAGE gel electrophoresis and transferred into nitrocellulose membrane $[25,26]$. The membrane was blocked by blocking buffer (containing 5\% nonfat dry milk) for $1 \mathrm{~h}$ and subsequently incubated with primary antibody at $4^{\circ} \mathrm{C}$ overnight. After primary antibody treatment, the membrane was washed with tris-buffered saline (TBST; containing $0.1 \%$ tween 20 ). The membrane was then treated with suitable HRP-conjugated secondary antibody at room temperature for $1 \mathrm{~h}$. The blots were developed by ECL substrate (Millipore, MA, USA) to detect the expressions of proteins in a ChemiDoc Touch Imaging
System (Bio-Rad, USA). The densitometric analysis was performed using Image Lab software (Bio-Rad, USA). Normalization of expression was done employing $\beta$-actin as a loading protein. The membranes were then subjected to mild stripping using stripping buffer containing 1\% SDS (pH 2.0) and glycine (25 mM), followed by treatments with respective primary and secondary antibodies for detecting the expressions of other proteins in the same membrane. The expressions of Bcl-2, Bax, cytochrome C, Apaf-1, cleaved caspase 9, cleaved caspase 3, Bid, Fas, cleaved caspase 8, total JNK, phospho-JNK (Tyr 183/Tyr 185), totalp38, phospho-p38 (Tyr 180/Tyr 182), p53, phospho-I $\kappa \mathrm{B} \alpha$ (Ser 32), and total $\mathrm{I} \kappa \mathrm{B} \alpha$, phospho-NF- $\kappa \mathrm{B}$ (p65) (Ser 536) were estimated. The experiments were performed in triplicate.

\subsection{In Vivo Bioassay}

2.4.1. Experimental Setup. The in vivo experiment was performed following established protocol by our group [6.7]. Twenty-four Swiss albino mice ( $₫$ ) were divided into four groups $(n=6)$ and were treated as follows:

Gr I: normal control, mice received only $1 \%$ tween 80 in distilled water ( $1 \mathrm{ml}$, p.o., once daily) for 15 days.

Gr II: toxic control, mice were treated with $\mathrm{NaAsO}_{2}$ ( $10 \mathrm{mg} / \mathrm{kg}$ body weight, p.o., once daily) for 10 days.

Gr III: animals were treated with CA $(10 \mathrm{mg} / \mathrm{kg}$ body weight, p.o., once daily for 15 days) began 5 days prior to the beginning of exposure to $\mathrm{NaAsO}_{2}(10 \mathrm{mg} / \mathrm{kg}$ body weight, p.o., once daily for 10 days), totalizing 15 days treatment period.

Gr IV: animals were treated with CA $(20 \mathrm{mg} / \mathrm{kg}$ body weight, p.o., once daily for 15 days) began 5 days prior to the beginning of exposure to $\mathrm{NaAsO}_{2}(10 \mathrm{mg} / \mathrm{kg}$ body weight, p.o., once daily for 10 days), totalizing 15 days treatment period.

The doses of CA were selected on the basis of in vitro observation, subacute toxicity studies, preliminary in vivo study (with limited number of animals). In subacute toxicity studies, CA (10 and $20 \mathrm{mg} / \mathrm{kg}$ body weight, p.o., once daily for 30 days) did not show any significant change in haematological, biochemical, and histological parameters when compared with normal mice (Supplementary Table 2 and Supplementary Figure 2).

The food intake and water intake were monitored on a daily basis. After 15 days, the mice were fasted overnight and were sacrificed by cervical dislocation under $\mathrm{CO}_{2}$ anesthesia. Before sacrificing the mice, body weight was recorded. For measurements of haematological parameters and biochemical markers in the sera, blood samples were collected from retro-orbital venous plexus after applying tetracaine ( $0.5 \%$, one drop) ophthalmic anesthetic drop to the eyes. The livers were excised and cleaned with PBS. The weight of liver was recorded. The organs were homogenized immediately in Tris- $\mathrm{HCl}(0.01 \mathrm{M})+$ EDTA $(0.001 \mathrm{M})$ buffers of $\mathrm{pH} 7.4$ and centrifuged $(12,000 \mathrm{~g})$ at $4^{\circ} \mathrm{C}$ for $30 \mathrm{~min}$ to obtain tissue homogenate. Urine samples were collected from the bladder and immediately stored at $-80^{\circ} \mathrm{C}$ [27]. A schematic overview of the in vivo assay has been depicted in Figure 2. 


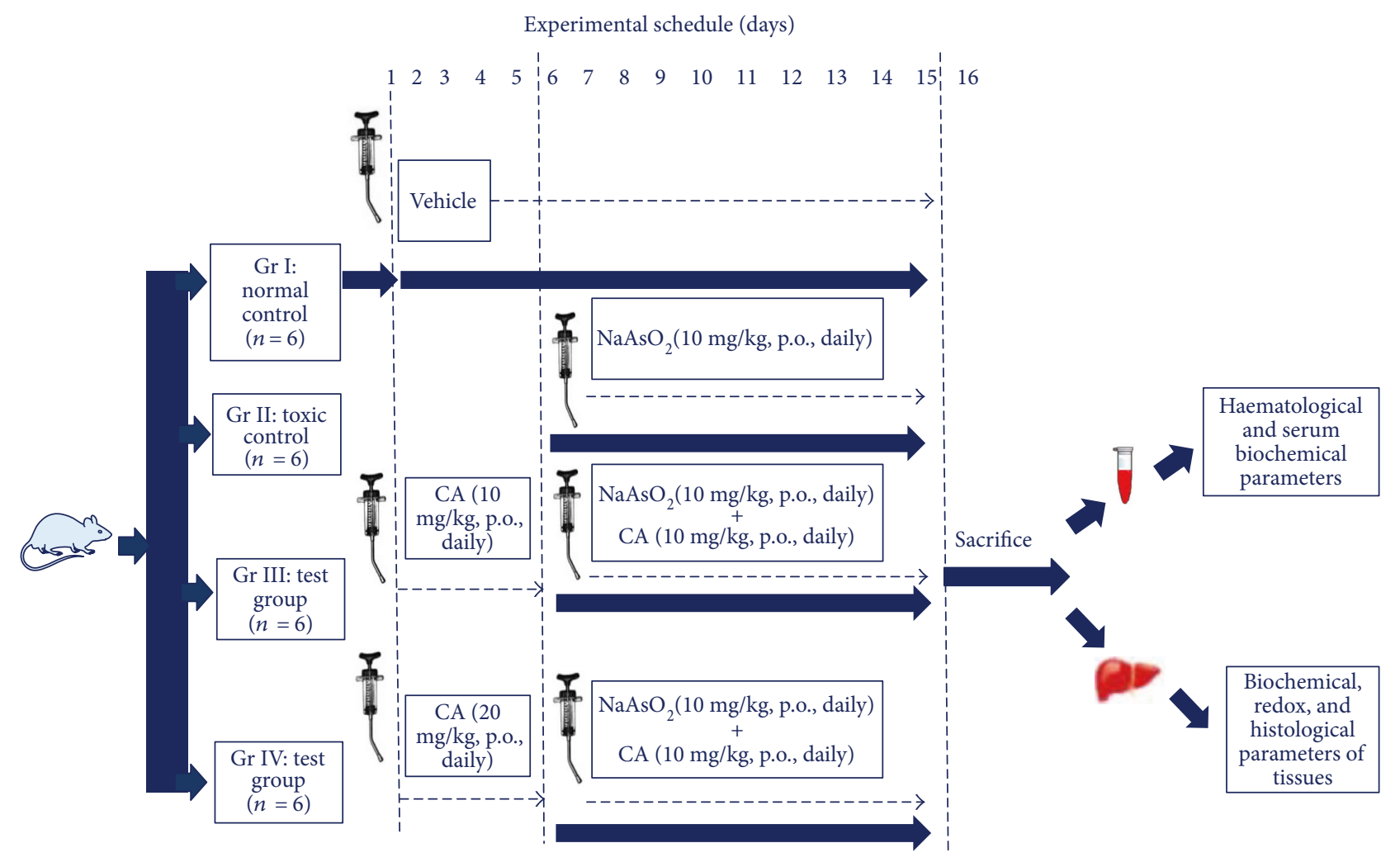

FIGURE 2: A schematic outline of in vivo experimental protocol.

2.4.2. Estimation of Haematological and Serum Biochemical Parameters. Total erythrocyte count was measured using a haemocytometer and haemoglobin content was estimated using a haemoglobinometer. The levels of alanine aminotransferase (ALT), aspartate aminotransferase (AST), creatine kinase $(\mathrm{CK})$, and lactate dehydrogenase (LDH) in the sera were estimated by commercially available kits (Span Diagnostics Limited, India) following manufacturer's protocol.

2.4.3. Assays for Hepatic and Urinary As. The As contents in liver and urine of experimental animals were analyzed following the method of Das et al. [28], using hydride generation system in atomic absorption spectrophotometer (Perkin Elmer model number 3100, USA).

2.4.4. Assays for Biochemical and Redox Markers in Liver. Cytosolic fractions from livers of experimental mice were isolated following subcellular fractionation protocol employing centrifugation methods mentioned by Abcam, Cambridge, MA, USA. Cytosolic ATP level in the hepatic tissue was estimated by the commercially available assay kit (Abcam, Cambridge, MA, USA) following manufacturer's protocol. The extent of DNA fragmentation was measured by the diphenylamine reaction as described by Lin et al. [29]. Briefly, the hepatic tissue was lysed with hypotonic lysing buffer $(10 \mathrm{mM}$ Tris, $\mathrm{pH} 8.0,1 \mathrm{mM}$ EDTA, $0.5 \%$ triton $\mathrm{X}$ $100)$, and the lysates were centrifuged to separate intact and fragmented fractions. Then the pellet and the supernatant were separately precipitated with $12.5 \%$ trichloroacetic acid. The DNA precipitates were heated to $90^{\circ} \mathrm{C}$ for $10 \mathrm{~min}$ in
$5 \%$ trichloroacetic acid and quantitatively estimated by colorimetric reaction with diphenylamine [29]. DNA oxidation was evaluated by RP-HPLC analysis and was represented as 7,8-hydroxy-2' -deoxyguaosine/2 2 -deoxyguaosine (8-OHdG/ $2-\mathrm{dG})$ ratio $[30,31]$. Briefly, DNA was isolated from hepatic tissue by pronase-ethanol method followed by enzymatic digestion as the protocol by Chepelev et al. [31]. 8-OHdG stock solution $(35 \mathrm{mmol} / \mathrm{l})$ was prepared in water, while 2 $\mathrm{dG}$ stock solution $(37 \mathrm{mmol} / \mathrm{l})$ was prepared in $0.5 \mathrm{~mol} / \mathrm{l}$ $\mathrm{NH}_{4} \mathrm{OH}$ [30]. The aliquots of $8-\mathrm{OHdG}$ and 2-dG stock solutions were adequately diluted first in water and finally in digested DNA samples to obtain working spiked solutions. Quantitative estimation was done in Dionex UltiMate 3000 HPLC system (Dionex, Germany), using a C-18 column $(250 \times 4.6 \mathrm{~mm}$, particle size $5 \mu)$ and electrochemical detector. The columns were preconditioned with $1 \mathrm{ml}$ acetonitrile, followed by $1 \mathrm{ml}$ water, and $1 \mathrm{ml}$ $100 \mathrm{mM} \mathrm{NaH}_{2} \mathrm{PO}_{4}$ (pH 6.0). For 8-OHdG analysis, the mobile phase ( $\mathrm{pH} 3.0)$ contained formic acid $(0.1 \mathrm{~mol} / \mathrm{l})$, citric acid ( $1.0 \mathrm{mmol} / \mathrm{l}), \mathrm{NaN}_{3}(7.7 \mathrm{mmol} / \mathrm{l})$, EDTA $(0.5 \mathrm{mmol} / \mathrm{l})$, diethylamine $(24.0 \mathrm{mmol} / \mathrm{l})$, and $4 \%$ acetonitrile. For $2-\mathrm{dG}$ analysis, the mobile phase comprised $\mathrm{NaH}_{2} \mathrm{PO}_{4}(50.0 \mathrm{mmol} / \mathrm{l})(\mathrm{pH} 4.5)$ and $4 \%$ acetonitrile. A flow rate of $1.0 \mathrm{ml} / \mathrm{min}$ was used. The applied potentials at the first and second electrodes for 8 -OHdG were 0.0 and +0.5 volts, respectively. While the applied potentials for $2-\mathrm{dG}$ were +0.4 and +0.8 volts at the first and second electrodes, respectively. The intercellular ROS, TBARS level, protein carbonylation, endogenous antioxidant enzymes, and GSH levels were assayed following established protocols [23]. 
2.4.5. Western Blotting of Signaling Proteins in Liver. The protein samples of liver for specific cellular components, namely cytosolic, mitochondrial, and nuclear fractions, were separated, employing sequential fractionation process [24]. The sample proteins $(20 \mu \mathrm{g})$ were resolved in $12 \%$ SDSPAGE gel electrophoresis and immunoblotted as mentioned in the earlier section. The expressions of Bcl-2, Bax, cytochrome C, Apaf-1, cleaved caspase 9, cleaved caspase 3, Bid, Fas, cleaved caspase 8, total JNK, phospho-JNK (Tyr 183/ Tyr 185), total-p38, phospho-p38 (Tyr 180/Tyr 182), p53, phospho- $\mathrm{I} \kappa \mathrm{B} \alpha$ (Ser 32 ), total $\mathrm{I} \kappa \mathrm{B} \alpha$, and phospho-NF- $\kappa \mathrm{B}$ (p65) (Ser 536) were estimated.

2.4.6. Histological Studies. The livers from the experimental mice were immediately fixed in $10 \%$ buffered formalin and were processed for paraffin sectioning. Sections $(\sim 5 \mu \mathrm{m})$ were stained with hematoxylin and eosin ( $\mathrm{H} \& \mathrm{E})$ for studying the histology of hepatic tissues [32].

2.4.7. Statistical Analysis. The experimental data were denoted as mean \pm SD. The data were statistically examined by one-way ANOVA followed by Dunnett's $t$-test using computerized GraphPad InStat (version 3.05), GraphPad software, USA. The values were considered significant when $p<0.05$ or 0.01 .

\subsection{In Silico Prediction}

2.5.1. Absorption, Distribution, Metabolism, and Excretion (ADME) Prediction. In silico ADME properties of CA were predicted using QikProp module of Maestro Schrödinger software [33]. Lipinski's rule of five (molecular weight $<500$, number of hydrogen bond donors $<5$, number of hydrogen bond acceptors $<10, \log P<5$ ) was also assessed, which helped in distinguishing between drug-like or non-drug-like profiles of a candidate molecule. Furthermore, some important ADME profiles, like oral absorptions, cell permeability, blood brain barrier, and so on of CA, were predicted in silico.

2.5.2. Molecular Docking and Postdocking Simulation Analysis. The high-resolution X-ray crystallographic structures of proteins were retrieved from Protein Data Bank (PDB) accessed on June 2017 [34]. The protein crystal structures for Bax (PDB ID: 4BD2), Bcl-2 (PDB: 4LXD), cytochrome C (PDB: 3ZCF), Apaf-1 (PDB: 1Z6T), caspase 9 (PDB: 2AR9), caspase 3 (PDB: 5I9B), Fas (PDB: 3EZQ), caspase 8 (PDB: 4PRZ), Bid (PDB: 4QVE), I $\kappa$ B (PDB: 4KIK), JNK (PDB: 4E73), NF- $\kappa$ B (PDB: 4IDV), p53 (PDB: 2XWR), and p38 (PDB: 3S3I) were downloaded in PDB format. To perform molecular docking, all proteins were prepared in Protein Preparation Wizard using Maestro in the Schrödinger suite [33] for addition of hydrogen atoms and to repair the faults like missing loops and steric clashes. Hence, protonation state was selected to be consistent in physiological $\mathrm{pH}$. To obtain the minimum energy structure, system was subjected to a restrained minimization using the OPLS2005 force field in Impact Refinement module (Impref). The ligand, CA, was processed in LigPrep module of Schrödinger [33]. Using the Receptor Grid generation panel, the receptor grid was generated. During the grid generation step, the binding site was defined by a rectangular box surrounding the cocrystallized ligand. The position and size of the active site were also determined. Molecular docking was performed using standard precision (SP) method of docking using Glide module [33] to evaluate the binding affinity between protein and ligand.

Following molecular docking, the protein-ligand complex was subjected to molecular dynamics (MD) simulation study using the Desmond program (Desmond Molecular Dynamics System and Maestro-Desmond Interoperability Tools, Schrödinger) [33]. The complex was neutralized by appropriate number of ions and surrounded by an orthorhombic shape of water box solvated by TIP3P (transferable intermolecular potential 3P) water model [35]. By adopting the SHAKE algorithm, bond lengths to $\mathrm{H}$ atoms and internal geometry of $\mathrm{H}_{2} \mathrm{O}$ molecules were constrained [36]. The simulation was carried out for each complex in equilibrated system of NPT ensemble at maximum $40 \mathrm{~ns}$ using the Nose-Hoover chain thermostat temperature at $300 \mathrm{~K}$ and Martyna-Tobias-Klein barostat bar pressure at 1.013 with a relaxation time of $1.0 \mathrm{ps}$ and $2.0 \mathrm{ps}$, respectively. Energy of system and atomic coordinate data were recorded in every 1.2 ps time intervals.

\section{Results}

\subsection{Effect of $\mathrm{CA}$ against $\mathrm{NaAsO}_{2}$ Intoxication In Vitro}

3.1.1. Dose-Dependent Effect of $\mathrm{NaAsO}_{2}$-Induced Cytotoxicity. Reduction of cell viability is the index of cytotoxicity. In search of the cytotoxic effect of $\mathrm{NaAsO}_{2}$, hepatocytes were incubated with $\mathrm{NaAsO}_{2}$ at different concentrations for $2 \mathrm{~h}$. The cell viability was reduced by $\mathrm{NaAsO}_{2}$ in a concentration-dependent manner (Figure 3(a)). The $\mathrm{IC}_{50}$ value has been found to be $11.6 \mu \mathrm{M}(\sim 12 \mu \mathrm{M})$. Based on the observed $\mathrm{IC}_{50}$ value, subsequent in vitro experiments were executed using $\mathrm{NaAsO}_{2}(12 \mu \mathrm{M})$ as a toxic control.

3.1.2. Effect of CA on Murine Hepatocytes. The hepatocytes incubated with CA $(1-6 \mu \mathrm{M})$ did not show any significant change in the cell viability up to $4 \mathrm{~h}$ of experimental duration when compared with normal/untreated hepatocytes ( $\sim 95.2 \%$ at $4 \mathrm{~h})$. However, cell viability was slightly/insignificantly reduced $(\sim 89.2 \%$ at $4 \mathrm{~h})$ with CA $(10 \mu \mathrm{M})$. The data were included as supplementary Figure 1.

3.1.3. Concentration-Dependent Cytoprotective Role of $C A$ against $\mathrm{NaAsO}_{2}$-Induced Cytotoxicity. $\mathrm{NaAsO}_{2} \quad(12 \mu \mathrm{M}$, $\left.\sim \mathrm{IC}_{50}\right)$ exposed hepatocytes exhibited significant $(p<0.01)$ reduction in cell viability up to $4 \mathrm{~h}$ (Figure $3(\mathrm{~b})$ ). Simultaneous treatment of hepatocytes with CA $(1-10 \mu \mathrm{M})$ and $\mathrm{NaAsO}_{2}(12 \mu \mathrm{M})$ significantly $(p<0.05-0.01)$ prevented the reduction in cell viability in a concentration-dependent manner up to $4 \mu \mathrm{M}$. However, cytoprotective effect of CA was further reduced $>4 \mu \mathrm{M}$ concentration when compared with $\mathrm{CA}$ $(4 \mu \mathrm{M})$. Based on the observation, the concentration of CA and the incubation time have been standardized to $4 \mu \mathrm{M}$ and $2 \mathrm{~h}$, respectively, for subsequent in vitro experiments. The CA $(4 \mu \mathrm{M})$ alone did not show any significant difference in redox parameters in isolated murine hepatocytes (Supplementary Table 1). 

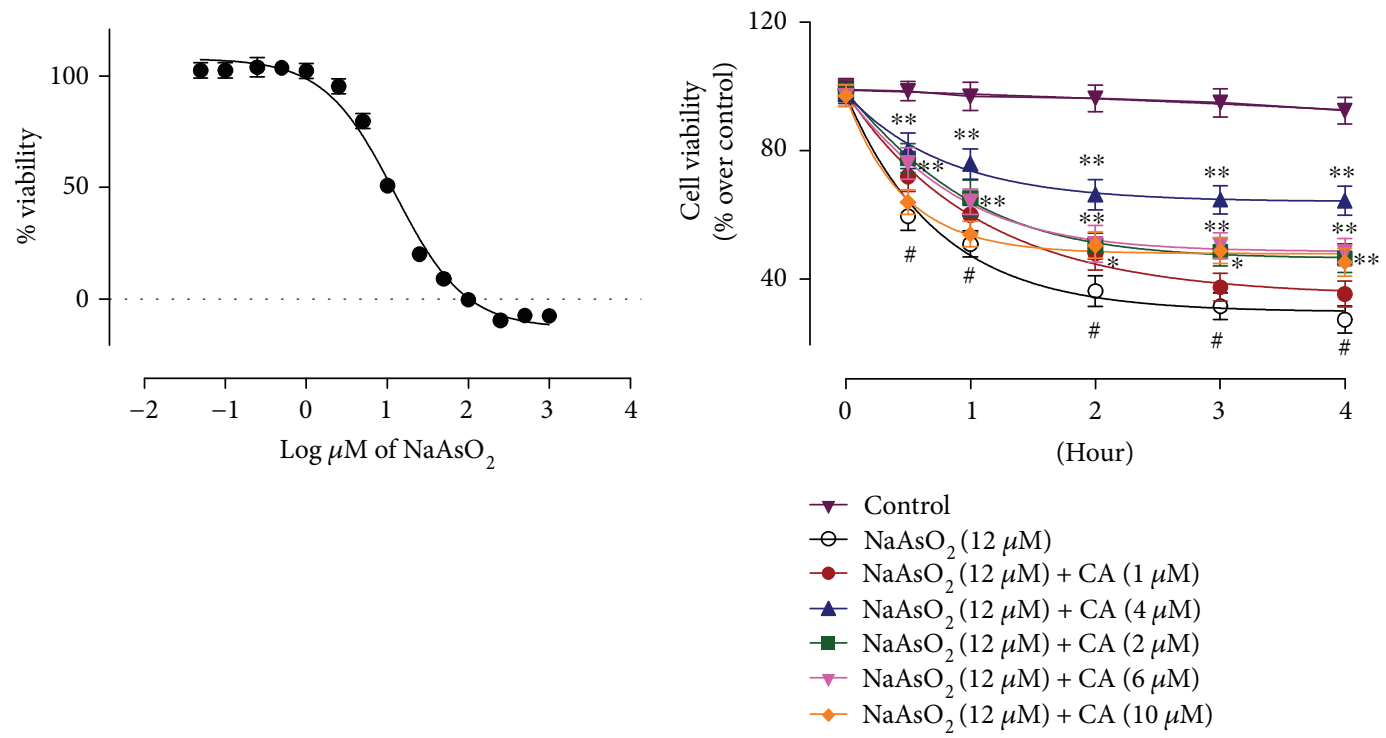

(a)

(b)

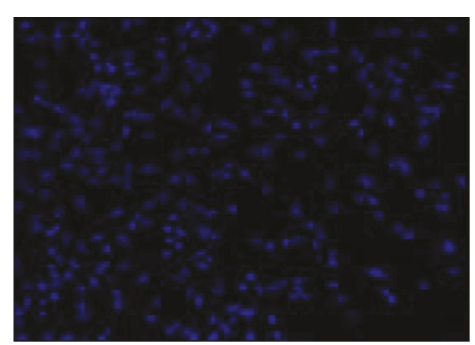

Control

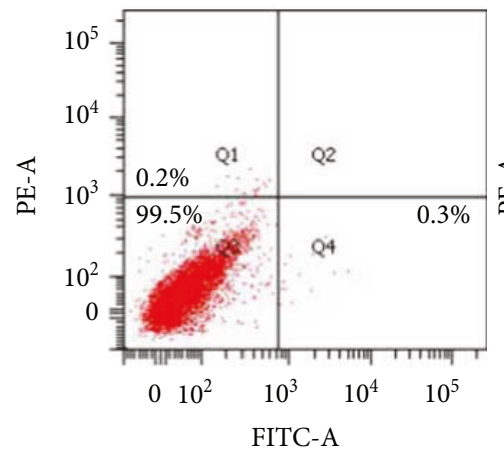

Control

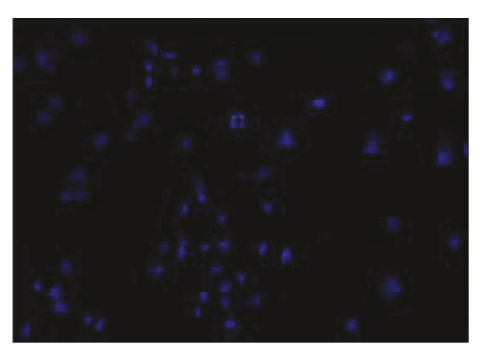

$\mathrm{NaAsO}_{2}(12 \mu \mathrm{M})$

(c)

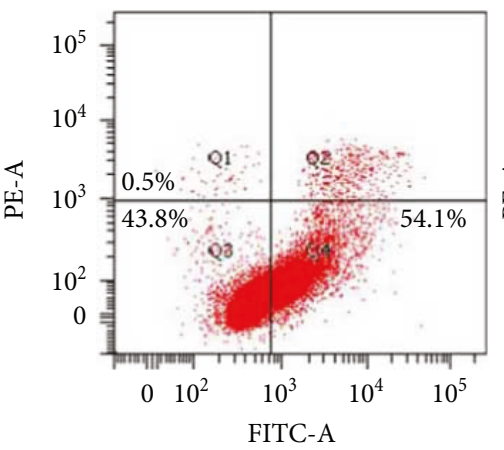

$\mathrm{NaAsO}_{2}(12 \mu \mathrm{M})$

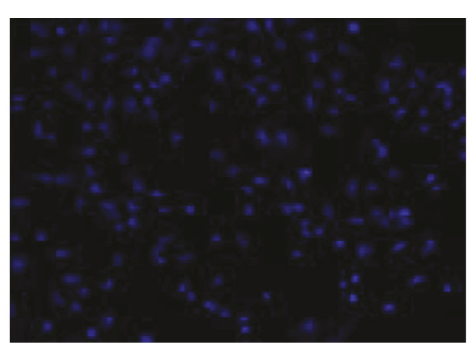

$\mathrm{NaAsO}_{2}(12 \mu \mathrm{M})+\mathrm{CA}(4 \mu \mathrm{M})$

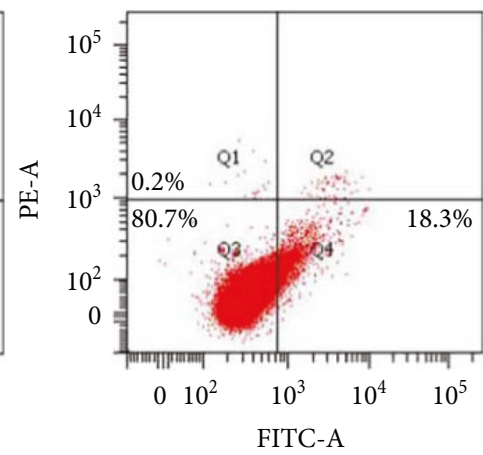

$\mathrm{NaAsO}_{2}(12 \mu \mathrm{M})+\mathrm{CA}(4 \mu \mathrm{M})$

(d)

Figure 3: The cell viability, image, and flow cytometric assays in the absence $\left(\mathrm{NaAsO}_{2}\right)$ and presence of $\mathrm{CA}(\mathrm{NaAsO}+\mathrm{CA})$ in vitro employing isolated murine hepatocytes. (a) Effect of $\mathrm{NaAsO}_{2}$ at different concentrations on cell viability in isolated murine hepatocytes. Values are represented as mean $\pm \mathrm{SD}(n=3)$. (b) Effect on cell viability in the absence $\left(\mathrm{NaAsO}_{2}\right)$ and presence of CA $(\mathrm{NaAsO}+\mathrm{CA})$. Values are represented as mean $\pm \mathrm{SD}(n=3)$. "Values significantly $(p<0.01)$ differ from normal control. ${ }^{*}$ Values significantly $(p<0.05)$ differ from toxic control. ${ }^{* *}$ Values significantly $(p<0.01)$ differ from toxic control. (c) Hoechst staining of hepatocytes in the absence $\left(\mathrm{NaAsO}_{2}\right)$ and presence of CA $\left(\mathrm{NaAsO}_{2}+\mathrm{CA}\right)$. (d) Percentage distribution of apoptotic and necrotic cells in the absence $\left(\mathrm{NaAsO}_{2}\right)$ and presence of $\mathrm{CA}\left(\mathrm{NaAsO}_{2}+\mathrm{CA}\right)$ analyzed by flow cytometric assay.

3.1.4. Effect on Hoechst Staining. The cytoprotective effect of CA has been estimated by Hoechst staining following visualization through fluorescence microscope (Figure 3(c)) of hepatocytes under different treatments. $\mathrm{NaAsO}_{2}(12 \mu \mathrm{M})$ treated hepatocytes exhibited significant reduction of visible nuclei; however, the visible nuclei exhibited explicit patterns of morphological changes, condensation, fragmentation of the nuclei, and chromatin condensation. Simultaneous 

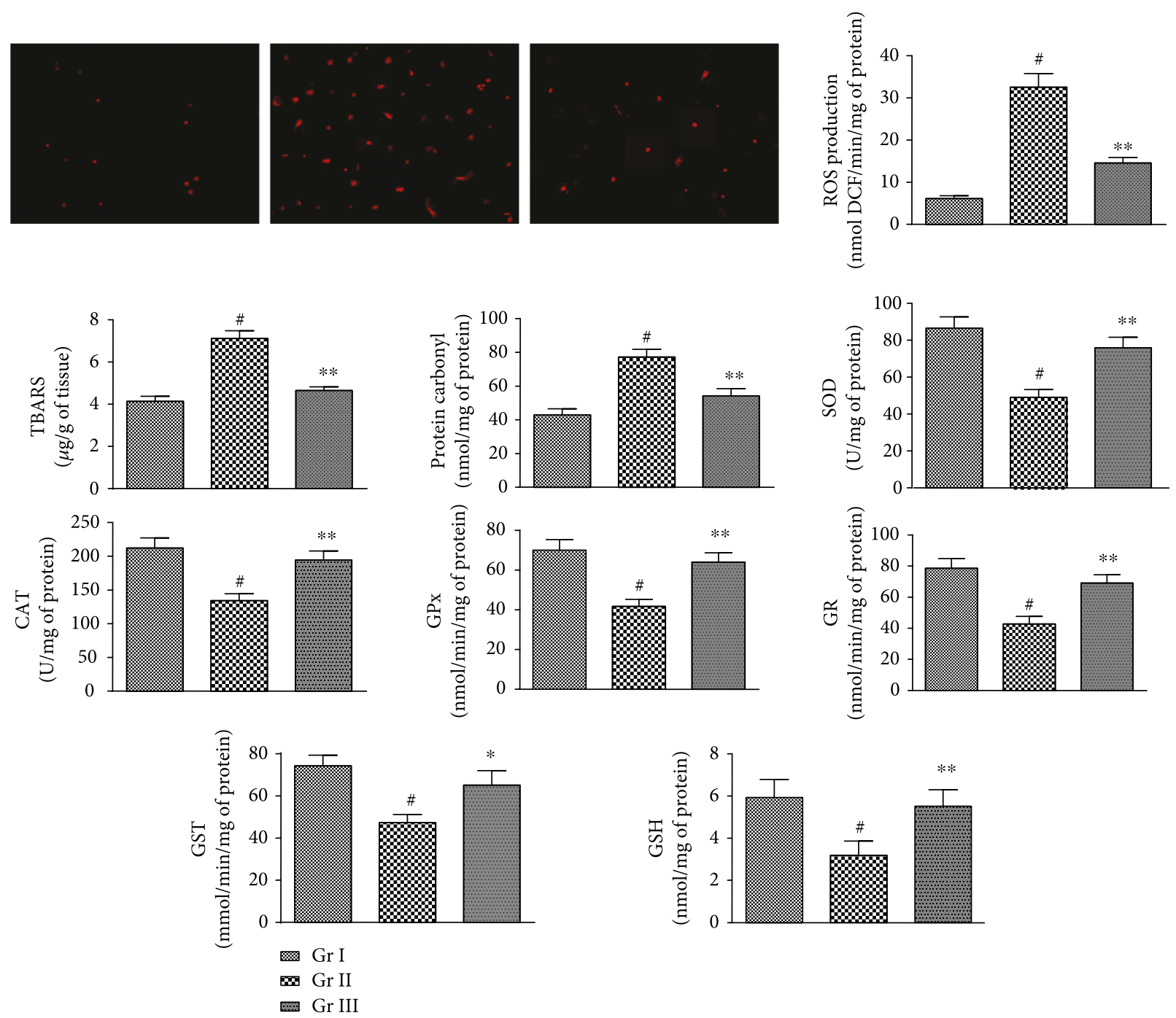

FIgURE 4: The effect on ROS accumulation, lipid peroxidation, protein carbonylation, and endogenous redox systems in the absence $\left(\mathrm{NaAsO}_{2}\right)$ and presence of $\mathrm{CA}\left(\mathrm{NaAsO}_{2}+\mathrm{CA}\right)$ in isolated murine hepatocytes. Values are represented as mean $\pm \mathrm{SD}(n=3)$. ${ }^{*} \mathrm{Values}$ significantly $(p<0.01)$ differ from normal control. ${ }^{*}$ Values significantly $(p<0.05)$ differ from toxic control. ${ }^{* *} V a l u e s$ significantly $(p<0.01)$ differ from toxic control. SOD unit, " $U$ " is defined as inhibition ( $\mu$ moles) of NBT-reduction/min. CAT unit " $U$ " is defined as $\mathrm{H}_{2} \mathrm{O}_{2}$ consumption/min. Gr I: normal control; Gr II: toxic control; Gr III: hepatocytes incubated with $\mathrm{NaAsO}_{2}(12 \mu \mathrm{M})$ along with CA $(4 \mu \mathrm{M})$.

incubation of hepatocytes with $\mathrm{CA}(4 \mu \mathrm{M})$ and $\mathrm{NaAsO}_{2}$ $(12 \mu \mathrm{M})$ could significantly attenuate the cytotoxic effect of $\mathrm{NaAsO}_{2}(12 \mu \mathrm{M})$ and could restore nuclear morphology to near-normal status.

3.1.5. Flow Cytometric Analysis. To investigate the nature of cell death, hepatocytes under different treatments were assessed by flow cytometric analysis. Flow cytometric data (Figure $3(\mathrm{~d})$ ) revealed that $\mathrm{NaAsO}_{2}(12 \mu \mathrm{M})$ treated hepatocytes exhibited very low PI staining $(\sim 0.5 \%)$ with very high annexin V-FITC binding $(\sim 54.1 \%)$ indicating majority of apoptotic cells. Simultaneous treatment of hepatocytes with $\mathrm{CA}(4 \mu \mathrm{M})$ and $\mathrm{NaAsO}_{2}(12 \mu \mathrm{M})$ resulted significant reduction in the count of the apoptotic cells $(\sim 18.3 \%)$ indicating a possible cytoprotective effect of CA against $\mathrm{NaAsO}_{2}(12 \mu \mathrm{M})$ induced cytotoxicity. The control group showed very little apoptotic $(\sim 0.3 \%)$ and necrotic $(\sim 0.2 \%)$ cells as compared with viable cells $(\sim 99.5 \%)$.

3.1.6. Effects on $\mathrm{NaAsO}_{2}$-Induced Alteration in Redox Status in Hepatocytes. The prophylactic effects of CA on $\mathrm{NaAsO}_{2}$ induced oxidative stress in isolated murine hepatocyte have been depicted in Figure 4. Overproduction of ROS is an index of redox-challenged cellular atmosphere. In this study, $\mathrm{NaAsO}_{2}(12 \mu \mathrm{M})$ incubated hepatocytes revealed significant $(p<0.01)$ enhance in ROS production in the hepatocytes as ostensible from fluorescence of DCF measured in fluorescence microscope. CA $(4 \mu \mathrm{M})$ could significantly $(p<0.01)$ reduce the $\mathrm{NaAsO}_{2}(12 \mu \mathrm{M})$ mediated ROS production in the hepatocytes. Overproduction of ROS causes oxidative damage of cellular macromolecules. In this study, $\mathrm{NaAsO}_{2}(12 \mu \mathrm{M})$ exposed hepatocytes exhibited significantly $(p<0.01)$ high level of thiobarbituric acid reactive substances 


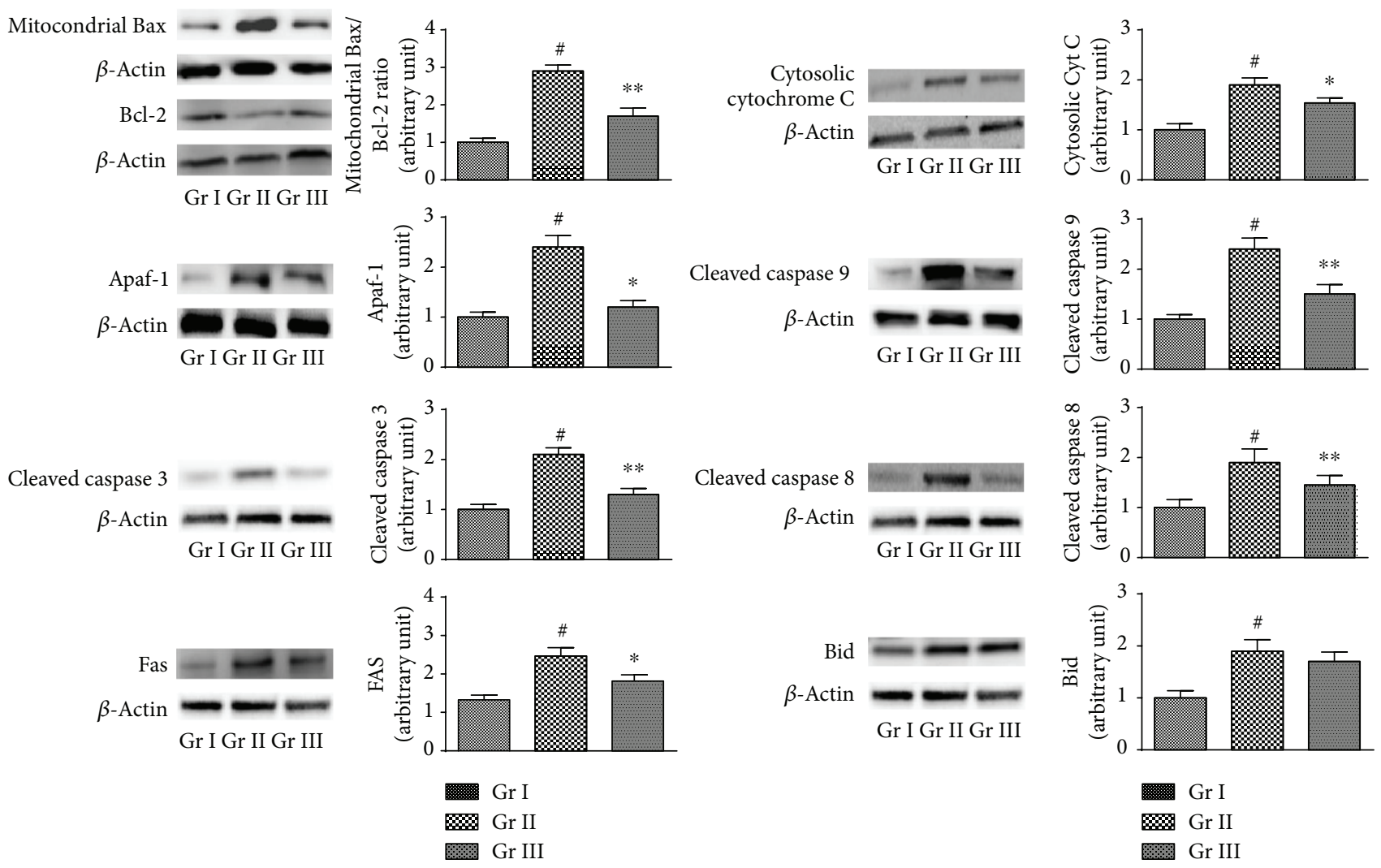

FIGURE 5: The effect on intrinsic and extrinsic apoptotic signaling in the absence $\left(\mathrm{NaAsO}_{2}\right)$ and presence of $\mathrm{CA}\left(\mathrm{NaAsO} \mathrm{O}_{2}+\mathrm{CA}\right)$ in vitro. The relative band intensities were assessed and the normal control band was allotted a random value of 1 . $\beta$-actin served as loading control. Values are expressed as mean \pm SD $(n=3)$. " Values significantly $(p<0.01)$ differ from normal control. *Values significantly $(p<0.05)$ differ from toxic control. ${ }^{* *}$ Values significantly $(p<0.01)$ differ from toxic control. Gr I: normal control; Gr II: toxic control; Gr III: hepatocytes incubated with $\mathrm{NaAsO}_{2}(12 \mu \mathrm{M})$ along with CA $(4 \mu \mathrm{M})$.

(TBARS) level. TBARS, a by-product of lipid peroxidation, is used as a marker to estimate the extent of lipid peroxidation. $\mathrm{NaAsO}_{2}(12 \mu \mathrm{M})$ exposed hepatocytes showed significant $(p$ $<0.01)$ escalation in the level of carbonylated protein. However, simultaneous treatment with CA $(4 \mu \mathrm{M})$ could significantly attenuate $\mathrm{NaAsO}_{2}$ mediated the lipid peroxidation $(<0.01)$ and protein carbonylation $(<0.01) . \mathrm{NaAsO}_{2}(12 \mu \mathrm{M})$ intoxication concomitantly creates a redox-challenged cellular environment via significant $(<0.01)$ depletion in the levels of endogenous antioxidant enzymes (SOD, CAT, GPx, GST, and GR) and GSH. However, treatment with CA $(4 \mu \mathrm{M})$ along with $\mathrm{NaAsO}_{2}(12 \mu \mathrm{M})$ could significantly reverse the $\mathrm{NaAsO}_{2}$-mediated changes in the levels of antioxidant enzymes $(p<0.05-0.01)$ and GSH $(p<0.01)$ in the murine hepatocytes.

3.1.7. Effects on Apoptotic Events in Hepatocytes. The prophylactic effects of CA on $\mathrm{NaAsO}_{2}$-induced intrinsic and extrinsic apoptotic signaling have been shown in Figure 5. Oxidative stress further promotes apoptosis via downregulation and upregulation in the transcriptions of antiapoptotic and proapoptotic signal proteins, respectively. In this study, the Western blot analysis revealed that $\mathrm{NaAsO}_{2}(12 \mu \mathrm{M})$ caused significant upregulation in the expression of the Bax (proapoptotic) protein in mitochondria with concomitant downregulation in the expression of $\mathrm{Bcl}-2$ (antiapoptotic) protein, resulting a significant $(p<0.01)$ increase in Bax/ Bcl-2 ratio in the hepatocytes. $\mathrm{NaAsO}_{2}(12 \mu \mathrm{M})$ exposure further promoted the release of cytochrome $\mathrm{C}$ to the cytosol evidenced from significant upregulation $(p<0.01)$ in the expression of cytosolic cytochrome $\mathrm{C}$ in murine hepatocytes. $\mathrm{NaAsO}_{2}(12 \mu \mathrm{M})$ treatment significantly $(p<0.01)$ activated Apaf-1 expression in the cytosol of murine hepatocytes, which further endorsed the cleavage of procaspases. Significant upregulations $(p<0.01)$ in the expressions of cleaved caspase 9 and cleaved caspase 3 were observed in $\mathrm{NaAsO}_{2}$ $(12 \mu \mathrm{M})$ exposed hepatocytes. However, CA $(4 \mu \mathrm{M})$ cotreatment could significantly $(p<0.05-0.01)$ reinstate the expressions of aforementioned intrinsic apoptotic proteins to near-normal status. In search of the effect on extrinsic pathway of apoptosis (mitochondria independent), Western blot analysis of FAS, cleaved caspase 8 , and Bid were performed. $\mathrm{NaAsO}_{2}(12 \mu \mathrm{M})$ exposed hepatocytes exhibited significant $(p<0.01)$ upregulations in the expressions of FAS, cleaved caspase 8 , and Bid. CA $(4 \mu \mathrm{M})$ cotreatment could significantly restore the expressions of FAS $(p<0.05)$ and cleaved caspase $8(p<0.01)$ to near-normal status. However, CA $(4 \mu \mathrm{M})$ was not found to be effective against Bid.

To investigate the proapoptotic effect of NF- $\kappa \mathrm{B}$, the signal proteins were immunoblotted (Figure 6). $\mathrm{NaAsO}_{2}$ $(12 \mu \mathrm{M})$ treatment could significantly $(p<0.01)$ stimulate the phosphorylation of cytosolic $\mathrm{I} \kappa \mathrm{B} \kappa$ and thereby could 


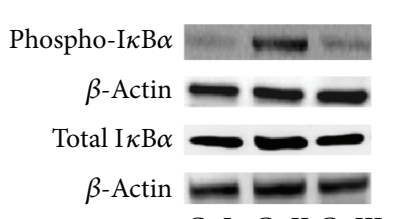

Gr I Gr II Gr III

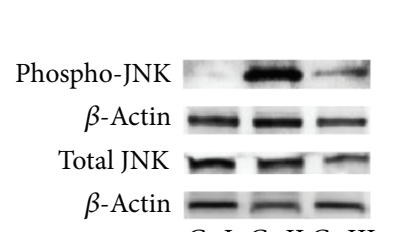

Gr I Gr II Gr III

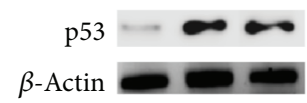

Gr I Gr II Gr III
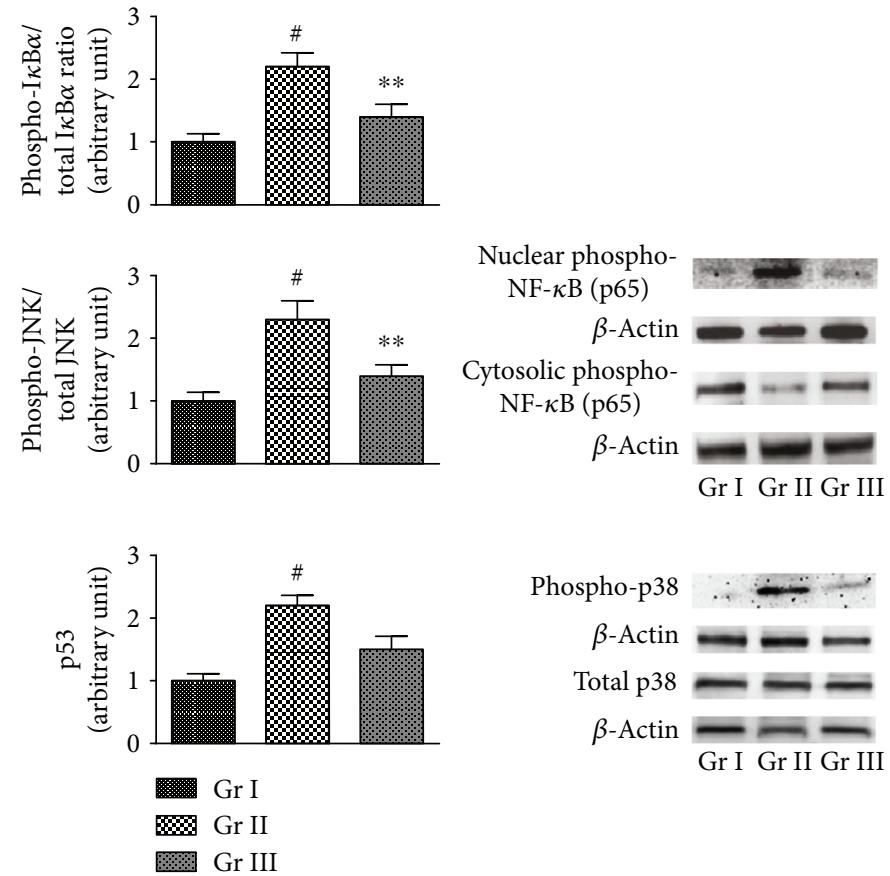

Gr I Gr II Gr III
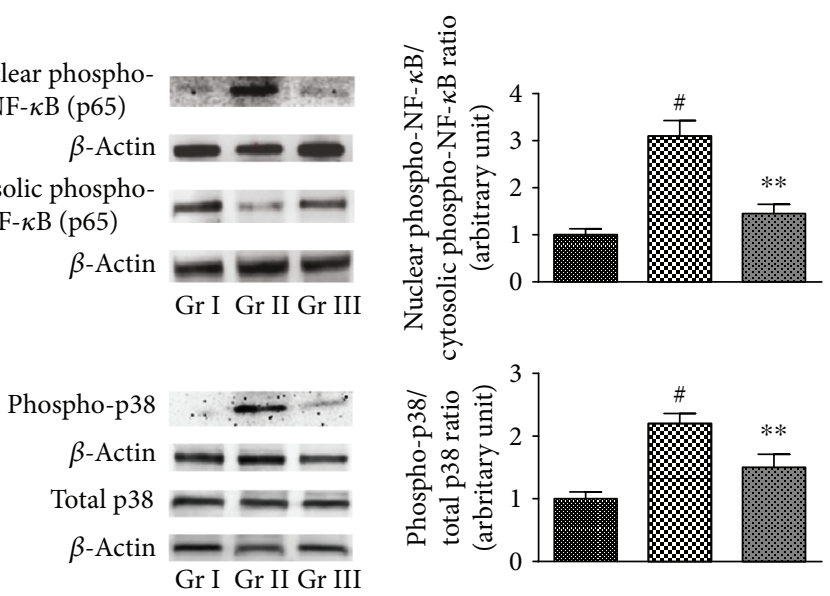

Figure 6: The effect on $\mathrm{I} \kappa \mathrm{B} \alpha, \mathrm{NF}-\kappa \mathrm{B}$, JNK, p38, and $\mathrm{p} 53$ signaling in the absence $\left(\mathrm{NaAsO}_{2}\right)$ and presence of $\mathrm{CA}(\mathrm{NaAsO}+\mathrm{CA})$ in vitro. The relative band intensities were assessed and the normal control band was allotted a random value of 1 . $\beta$-actin served as loading control. Values are expressed as mean \pm SD $(n=3) .{ }^{*}$ Values significantly $(p<0.01)$ differ from normal control. ${ }^{*}$ Values significantly $(p<0.05)$ differ from toxic control. ${ }^{* *}$ Values significantly $(p<0.01)$ differ from toxic control. Gr I: normal control; Gr II: toxic control; Gr III: hepatocytes incubated with $\mathrm{NaAsO}_{2}(12 \mu \mathrm{M})$ along with $\mathrm{CA}(4 \mu \mathrm{M})$.

TABLE 1: Effects on body weight, liver weight, hepatic As content, and urinary As content in the absence $\left(\mathrm{NaAsO}_{2}\right)$ and presence of CA $\left(\mathrm{CA}+\mathrm{NaAsO}_{2}\right)$ in mice.

\begin{tabular}{lccrc}
\hline Parameters & Gr I & Gr II & Gr III & Gr IV \\
\hline Body weight $(\mathrm{g})$ & $28.16 \pm 3.11$ & $21.77 \pm 2.08^{\#}$ & $26.08 \pm 3.01^{*}$ & $1.92 \pm 3.33^{*}$ \\
Liver weight $(\mathrm{g})$ & $1.24 \pm 0.21$ & $1.15 \pm 7.29$ & $1.17 \pm 0.13$ & $0.35 \pm 0.04^{*}$ \\
Liver As $(\mu \mathrm{g} / \mathrm{g}$ of tissue) & $0.06 \pm .0001$ & $0.51 \pm 0.04^{\#}$ & 0.25 \\
Urinary As $(\mu \mathrm{g} / \mathrm{g}$ of creatinine) & $2.34 \pm 0.31$ & $19.65 \pm 2.17^{\#}$ & $23.67 \pm 2.98^{*}$ & $26.01 \pm 3.22^{* *}$ \\
\hline
\end{tabular}

Values are expressed as mean $\pm \mathrm{SD}(n=6) .{ }^{*}$ Values differ significantly from normal control $(p<0.01) .{ }^{*}$ Values differ significantly from $\mathrm{NaAs} \mathrm{O}_{2}$ control $(p<0.05) .{ }^{* *}$ Values differ significantly from $\mathrm{NaAsO}_{2}$ control $(p<0.01)$. Gr I: normal control; Gr II: toxic control; Gr III: CA $(10 \mathrm{mg} / \mathrm{kg})+\mathrm{NaAsO}{ }_{2}$ $(10 \mathrm{mg} / \mathrm{kg}) ;$ Gr IV: CA $(20 \mathrm{mg} / \mathrm{kg})+\mathrm{NaAsO}_{2}(10 \mathrm{mg} / \mathrm{kg})$.

activate NF- $\kappa \mathrm{B} \quad(\mathrm{p} 65)$ signaling. A significant $(p<0.01)$ translocation of NF- $\kappa \mathrm{B}$ (p65) to the nucleus was visualized in $\mathrm{NaAsO}_{2}(12 \mu \mathrm{M})$ exposed hepatocytes. However, CA $(4 \mu \mathrm{M})$ could significantly $(p<0.01)$ attenuate the aforementioned NF- $\kappa \mathrm{B}$ signaling pathway within the hepatocytes. ROS can also trigger the mitogen-activated protein kinases (MAPK). In this study, $\mathrm{NaAsO}_{2}(12 \mu \mathrm{M})$ could significantly $(p<0.01)$ stimulate the phosphorylation of JNK and p38 (Figure 6). However, CA $(4 \mu \mathrm{M})$ could significantly $(p<0.01)$ downregulate the $\mathrm{NaAsO}_{2}(12 \mu \mathrm{M})$ mediated phosphorylation of JNK and p38. On the other hand, $\mathrm{NaAsO}_{2}(12 \mu \mathrm{M})$ could significantly $(p<0.01)$ upregulate p53 signaling, while CA $(4 \mu \mathrm{M})$ was not found to be effective against $\mathrm{p} 53$.

\subsection{Effects of $\mathrm{CA}$ against $\mathrm{NaAsO}_{2}$ Intoxication In Vivo}

3.2.1. Effect on Body Weight, Liver Weight, Hepatic As Content, and Urinary As Content. During the tenure of experiment, no significant change in food and water intake was recorded in the animals of either of experimental group. $\mathrm{NaAsO}_{2}(10 \mathrm{mg} / \mathrm{kg})$ treated mice exhibited significant $(p<0.01)$ reduction in the body weight; however, simultaneous administration of CA (10 and $20 \mathrm{mg} / \mathrm{kg})$ along with $\mathrm{NaAsO}_{2}(10 \mathrm{mg} / \mathrm{kg})$ could significantly $(p<$ $0.05)$ restore the body weight to near-normal status (Table 1). No significant difference in liver weight was observed in the experimental mice of either group. $\mathrm{NaAsO}_{2} \quad(10 \mathrm{mg} / \mathrm{kg})$ exposed mice exhibited significant $(p<0.01)$ increase in the accumulation of As in the liver coupled with significantly $(p<0.01)$ poor urinary clearance of As when compared with normal mice. On the other hand, simultaneous administration of CA (10 and $20 \mathrm{mg} / \mathrm{kg}$ ) along with $\mathrm{NaAsO}_{2}(10 \mathrm{mg} / \mathrm{kg})$ could significantly $(p<0.05-0.01)$ promote the As clearance resulting significantly $(p<0.05)$ low hepatic As content. 
TABLE 2: Effects on haematological and serum biochemical parameters in the absence $\left(\mathrm{NaAsO}_{2}\right)$ and presence of $\mathrm{CA}\left(\mathrm{CA}+\mathrm{NaAsO} \mathrm{O}_{2}\right)$ in mice.

\begin{tabular}{lcccc}
\hline Parameters & Gr I & Gr II & Gr III & Gr IV \\
\hline Total erythrocyte count $\left(\times 10^{6} / \mathrm{mm}^{3}\right)$ & $6.28 \pm 0.42$ & $3.22 \pm 0.34^{\#}$ & $4.04 \pm 0.25^{*}$ & $5.19 \pm 0.67^{* *}$ \\
Haemoglobin (g/dl) & $8.76 \pm 0.72$ & $4.89 \pm 0.43^{\#}$ & $6.12 \pm 0.48^{*}$ & $6.88 \pm 0.87^{* *}$ \\
ALT (IU/I) & $68.54 \pm 5.81$ & $112.98 \pm 9.63^{\#}$ & $89.85 \pm 7.62^{* *}$ & $82.17 \pm 6.15^{* *}$ \\
AST (IU/I) & $58.12 \pm 4.63$ & $82.91 \pm 7.29^{\#}$ & $73.62 \pm 5.82^{*}$ & $64.57 \pm 5.51^{* *}$ \\
CK (IU/mg protein) & $10.87 \pm 1.05$ & $18.65 \pm 1.24^{\#}$ & $14.22 \pm 0.98^{* *}$ & $13.78 \pm 1.33^{* *}$ \\
LDH (U/l) & $171.34 \pm 13.42$ & $252.67 \pm 21.50^{\#}$ & $198.33 \pm 20.12^{* *}$ & $187.54 \pm 17.72^{* *}$ \\
\hline
\end{tabular}

Values are expressed as mean $\pm \mathrm{SD}(n=6) .{ }^{*}$ Values differ significantly from normal control $(p<0.01) .{ }^{*}$ Values differ significantly from $\mathrm{NaAsO}_{2}$ control $(p<0.05) .{ }^{* *}$ Values differ significantly from $\mathrm{NaAsO}_{2}$ control $(p<0.01)$. Gr I: normal control; Gr II: toxic control; $\mathrm{Gr}$ III: $\mathrm{CA}(10 \mathrm{mg} / \mathrm{kg})+\mathrm{NaAsO}{ }_{2}$ $(10 \mathrm{mg} / \mathrm{kg}) ; \mathrm{Gr}$ IV: CA $(20 \mathrm{mg} / \mathrm{kg})+\mathrm{NaAsO}_{2}(10 \mathrm{mg} / \mathrm{kg})$.

3.2.2. Effects on Blood Parameters. Blood parameters give crucial impression of pathological state within the system. The effects of CA on blood parameters of experimental mice were reported in Table $2 . \mathrm{NaAsO}_{2}(10 \mathrm{mg} / \mathrm{kg})$ treated mice exhibited significant $(p<0.01)$ reduction in erythrocyte counts and haemoglobin level. However, simultaneous administration of CA (10 and $20 \mathrm{mg} / \mathrm{kg}$ ) along with $\mathrm{NaAsO}_{2}$ $(10 \mathrm{mg} / \mathrm{kg})$ could significantly $(p<0.05-0.01)$ restore the erythrocyte counts and haemoglobin level $(p<0.01)$ to near-normal status. $\mathrm{NaAsO}_{2}(10 \mathrm{mg} / \mathrm{kg})$ treatment caused significant $(p<0.01)$ increase in ALT, AST, LDH, and CK levels in the sera of experimental mice. However, concurrent administration of CA (10 and $20 \mathrm{mg} / \mathrm{kg}$ ) along with $\mathrm{NaAsO}_{2}$ $(10 \mathrm{mg} / \mathrm{kg})$ could significantly $(p<0.05-0.01)$ revert the serum biochemical parameters to near-normal status.

3.2.3. Effects on Redox Status in Liver. In in vivo assay, $\mathrm{NaAsO}_{2} \quad(10 \mathrm{mg} / \mathrm{kg})$ treated mice exhibited significant $(p<0.01)$ elevation in the level of intracellular ROS within the hepatic tissue (Figure 7). However, simultaneous administration of CA (10 and $20 \mathrm{mg} / \mathrm{kg}$ ) along with $\mathrm{NaAsO}_{2}$ $(10 \mathrm{mg} / \mathrm{kg})$ could significantly $(p<0.01)$ attenuate intracellular ROS production in the liver (Figure 6). Significant $(p<0.01)$ upregulations in lipid peroxidation and protein carbonylation were observed in the liver of $\mathrm{NaAsO}_{2}$ $(10 \mathrm{mg} / \mathrm{kg})$ exposed mice. On the other hand, CA (10 and $20 \mathrm{mg} / \mathrm{kg})$ treatment could significantly $(p<0.05-0.01)$ reinstate lipid peroxidation and protein carbonylation in the hepatic tissue of the experimental mice to near-normal status (Figure 7$). \mathrm{NaAsO}_{2}(10 \mathrm{mg} / \mathrm{kg})$ further potentiated oxidative stress via significant $(p<0.01)$ depletion in the levels of GSH and endogenous antioxidant enzymes (SOD, CAT, GPx, GR, and GST) in the hepatic tissue (Figure 7). However, simultaneous administration of CA (10 and $20 \mathrm{mg} / \mathrm{kg}$ ) along with $\mathrm{NaAsO}_{2}(10 \mathrm{mg} / \mathrm{kg})$ could significantly $(p<0.05-0.01)$ revert GSH and endogenous antioxidant enzymes to near-normal status (Figure 7).

3.2.4. Effects in the Expressions of Signal Proteins in the Liver. In this study, the expressions of different apoptotic proteins in the liver of experimental mice were assessed by Western blotting (Figure 8). Significant upregulations $(p<0.01)$ in the expressions of proapoptotic Bax protein in the mitochondria and concomitant downregulations $(p<$ $0.01)$ in the expressions of antiapoptotic-Bcl-2 protein in the cellular fraction were observed in the liver of $\mathrm{NaAsO}_{2}$ $(10 \mathrm{mg} / \mathrm{kg})$ treated mice. In this study, significant $(p<0.01)$ high mitochondrial $\mathrm{Bax} / \mathrm{Bcl}-2$ ratio was observed in the hepatic tissue of $\mathrm{NaAsO}_{2}(10 \mathrm{mg} / \mathrm{kg})$ treated mice. However, treatment with CA (10 and $20 \mathrm{mg} / \mathrm{kg}$ ) along with $\mathrm{NaAsO}_{2}$ $(10 \mathrm{mg} / \mathrm{kg})$ could significantly $(p<0.05-0.01)$ reciprocate As-mediated alteration of $\mathrm{Bax} / \mathrm{Bcl}-2$ ratio in the liver of experimental animals. $\mathrm{NaAsO}_{2}(10 \mathrm{mg} / \mathrm{kg})$ treated mice revealed significant $(p<0.01)$ upregulation of cytosolic cytochrome $\mathrm{C}$ in the hepatic tissue, which suggested the release of cytochrome $\mathrm{C}$ into cytosol from mitochondria. On other hand, treatment with CA (10 and $20 \mathrm{mg} / \mathrm{kg}$ ) along with $\mathrm{NaAsO}_{2} \quad(10 \mathrm{mg} / \mathrm{kg})$ could significantly $(p<0.05)$ attenuate As-provoked cytochrome $\mathrm{C}$ release to cytosol. Significant upregulations $(p<0.01)$ in the expressions of Apaf-1 were recorded in the liver of $\mathrm{NaAsO}_{2}$-exposed mice. CA $(20 \mathrm{mg} / \mathrm{kg})$ treatment along with $\mathrm{NaAsO}_{2}$ $(10 \mathrm{mg} / \mathrm{kg})$ could significantly $(p<0.05)$ downregulate the expression of Apaf-1 in the hepatic tissue of experimental mice. $\mathrm{NaAsO}_{2}(10 \mathrm{mg} / \mathrm{kg})$ treated mice exhibited significant $(p<0.01)$ upregulation in the expressions of cleaved caspases 3 and 9 in the liver of experimental mice. However, treatment with CA (10 and $20 \mathrm{mg} / \mathrm{kg}$ ) along with $\mathrm{NaAsO}_{2} \quad(10 \mathrm{mg} / \mathrm{kg})$ could significantly reciprocate the expressions of cleaved caspases $3(p<0.05-0.01)$ and 9 $(p<0.01)$ in the liver of experimental mice. To study the effect of $\mathrm{NaAsO}_{2}$ on death receptor-mediated apoptosis, immunoblot analysis of FAS, Bid and cleaved caspase 8 was performed. $\mathrm{NaAsO}_{2}(10 \mathrm{mg} / \mathrm{kg})$ treated mice exhibited significant $(p<0.01)$ upregulation in the expressions of the FAS, Bid, and cleaved caspase 8 in the hepatic tissue, which advocated simultaneous engrossment of the extrinsic pathway of apoptosis. Treatment with CA (10 and $20 \mathrm{mg} / \mathrm{kg}$ ) along with $\mathrm{NaAsO}_{2}(10 \mathrm{mg} / \mathrm{kg})$ could significantly reciprocate the As-mediated alteration in the expressions of FAS $(p<0.05)$ and cleaved caspase $8(p<0.01)$. However, CA (10 and $20 \mathrm{mg} / \mathrm{kg}$ ) treatment did not exhibit any significant change in As-provoked Bid expression in the liver of experimental animals.

To investigate the effect on NF- $\kappa \mathrm{B}$, the signaling, $\mathrm{NaAsO}_{2}$ $(10 \mathrm{mg} / \mathrm{kg})$ treatment could significantly $(p<0.01)$ stimulate 

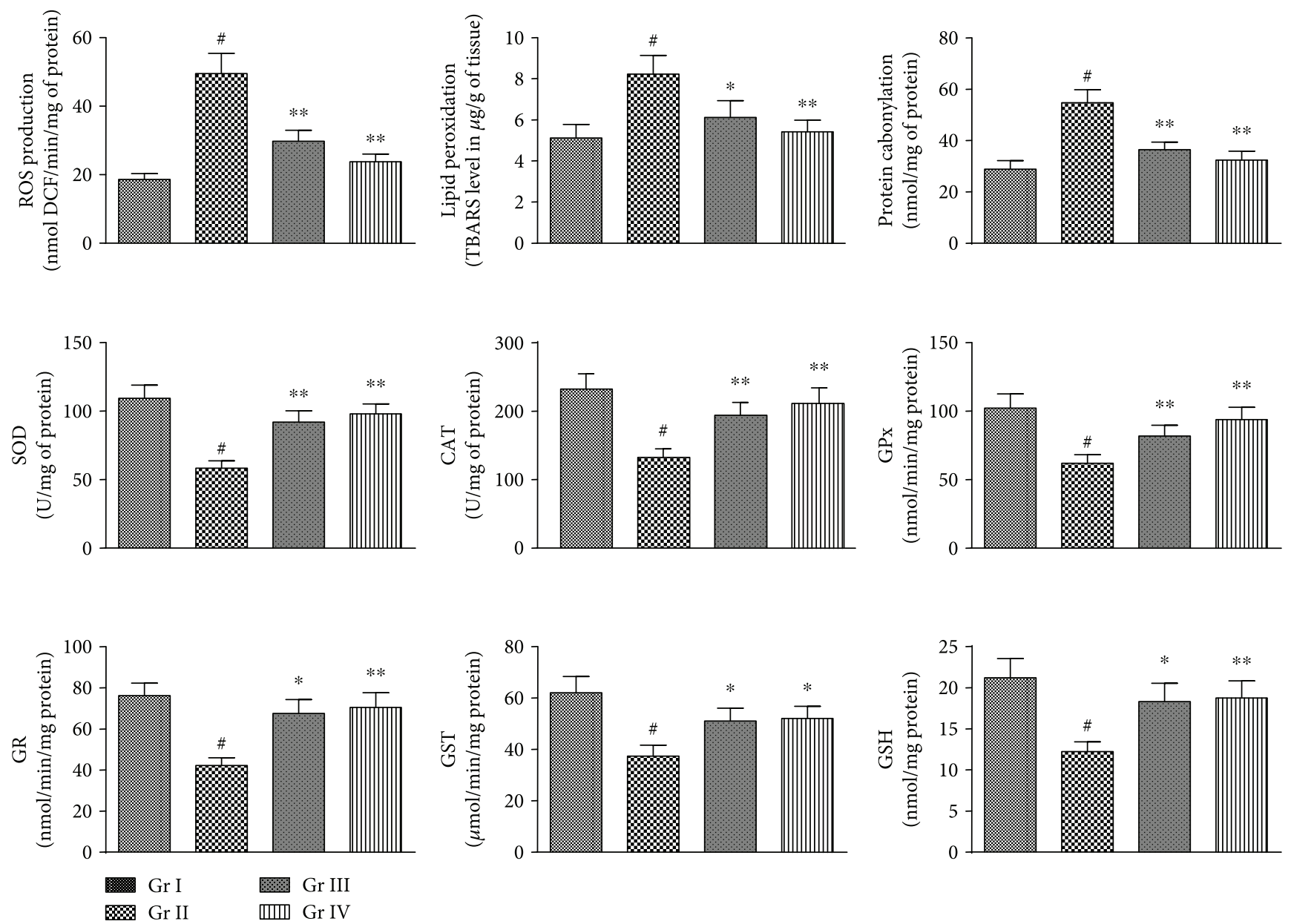

FIGURE 7: The effect on ROS accumulation, lipid peroxidation, protein carbonylation, and endogenous redox systems in the absence $\left(\mathrm{NaAsO}_{2}\right)$ and presence of $\mathrm{CA}\left(\mathrm{NaAsO}_{2}+\mathrm{CA}\right)$ in vivo in the liver of experimental mice. Values are represented as mean $\pm \mathrm{SD}(n=6)$. "Values significantly $(p<0.01)$ differ from normal control. "Values significantly $(p<0.01)$ differ from normal control. ${ }^{*}$ Values significantly $(p<0.05)$ differ from toxic control. ** Values significantly $(p<0.01)$ differ from toxic control. SOD unit " $U$ " is defined as inhibition ( $\mu$ moles) of NBT-reduction/min. CAT unit " $U$ " is defined as $\mathrm{H}_{2} \mathrm{O}_{2}$ consumption/min. Gr I: normal control; Gr II: toxic control; Gr III: CA $(10 \mathrm{mg} / \mathrm{kg})+\mathrm{NaAsO}_{2}(10 \mathrm{mg} / \mathrm{kg})$, Gr IV: CA $(20 \mathrm{mg} / \mathrm{kg})+\mathrm{NaAsO}_{2}(10 \mathrm{mg} / \mathrm{kg})$.

the phosphorylation of cytosolic $\mathrm{I} \kappa \mathrm{B} \alpha$ and thereby could significantly trigger the translocation of phosphorylated NF- $k \mathrm{~B}$ (p 65) $(p<0.01)$ to the nucleus (Figure 9). However, CA $(10$ and $20 \mathrm{mg} / \mathrm{kg}$ ) along with $\mathrm{NaAsO}_{2}(10 \mathrm{mg} / \mathrm{kg})$ could significantly $(p<0.05-0.01)$ attenuate the aforementioned NF- $\kappa \mathrm{B}$ signaling pathway in the liver of experimental mice (Figure 9). In this study, $\mathrm{NaAsO}_{2}(10 \mathrm{mg} / \mathrm{kg})$ could significantly $(p<0.01)$ upregulate the phosphorylation of JNK and p38 (Figure 9). The treatment with CA (10 and $20 \mathrm{mg} / \mathrm{kg}$ ) along with $\mathrm{NaAsO}_{2}(10 \mathrm{mg} / \mathrm{kg})$ could significantly $(p<0.01)$ reciprocate the phosphorylation of JNK and p38 in the hepatic tissue of experimental mice (Figure 9). However, CA (10 and $20 \mathrm{mg} / \mathrm{kg}$ ) could not counteract with the $\mathrm{NaAsO}_{2}(10 \mathrm{mg} / \mathrm{kg})$ mediated p53 upregulation in the liver of experimental mice (Figure 9).

3.2.5. Effects on ATP Levels, DNA Fragmentation, and DNA Oxidation in the Liver. In this study, $\mathrm{NaAsO}_{2}(10 \mathrm{mg} / \mathrm{kg})$ treatment caused significant $(p<0.01)$ elevation in the level of cytosolic ATP in the hepatic tissue of experimental mice
(Figure 10). The experimental observation could be substantiated with the establishment of apoptotic incidence within the liver. $\mathrm{NaAsO}_{2}(10 \mathrm{mg} / \mathrm{kg})$ mediated significant $(p<0.01)$ upregulations of DNA fragmentation and oxidation further confirmed the establishment of As-mediated cytotoxic events within the hepatic tissue of mice (Figure 10). On the other hand, concomitant treatment with CA (10 and $20 \mathrm{mg} / \mathrm{kg}$ ) along with $\mathrm{NaAsO}_{2}(10 \mathrm{mg} / \mathrm{kg})$ could significantly $(p<0.05-0.01)$ reduce cytosolic ATP level, DNA fragmentation, and DNA oxidation in the hepatic tissue of experimental mice close to the normal status (Figure 10).

3.2.6. Effects on the Histology of the Liver. The histological sections of livers of experimental mice were depicted in Figures 11(a) and (b). The liver section of $\mathrm{NaAsO}_{2}$ $(10 \mathrm{mg} / \mathrm{kg})$ exposed mice exhibited diffused portal veins (red arrows), damaged hepatocytes with infiltrating leukocytes (green arrows), vacuolated cytoplasm (blue arrows), and induction of apoptosis (yellow arrows) when compared with the liver section of normal mice. However, 


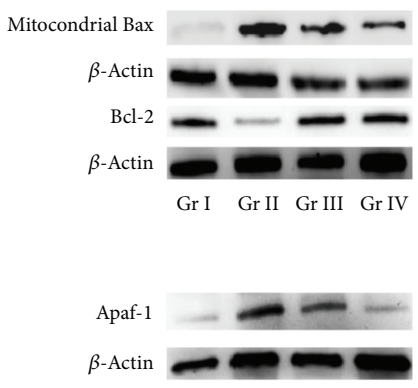

GrI Gr II Gr III GrIV
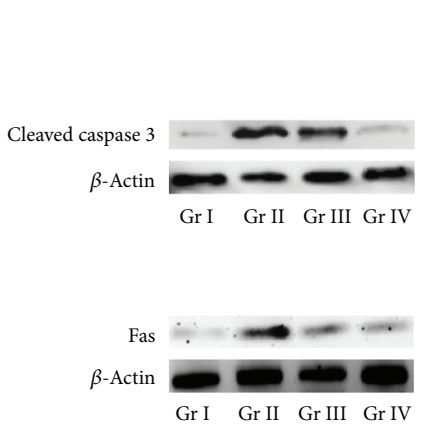
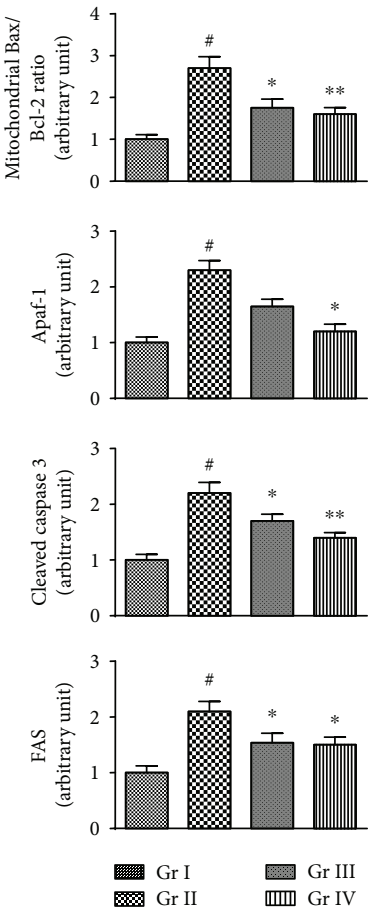

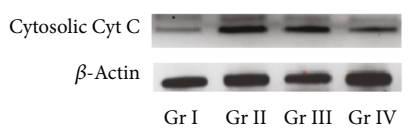

Gr I Gr II Gr III GrIV
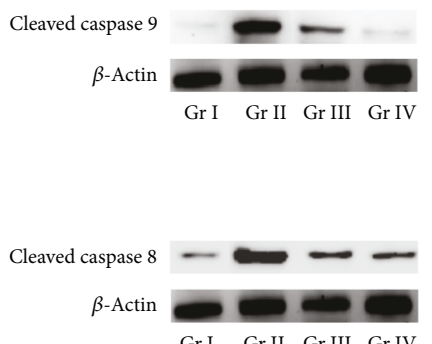

GrI GrII GrIII GrIV

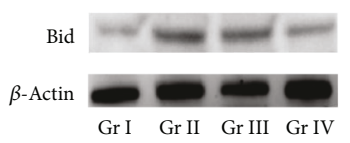

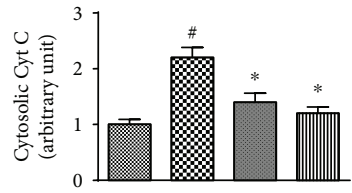
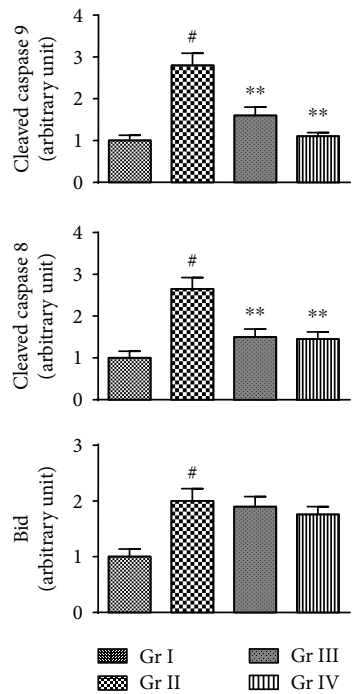

Figure 8: The effect on intrinsic and extrinsic apoptotic signaling in the absence $\left(\mathrm{NaAsO}_{2}\right)$ and presence of $\mathrm{CA}\left(\mathrm{NaAsO} \mathrm{O}_{2}+\mathrm{CA}\right)$ in vivo in the liver of experimental mice. The relative band intensities were assessed and the normal control band was allotted a random value of 1 . $\beta$-actin served as loading control. Values are expressed as mean $\pm \mathrm{SD}(n=6) .{ }^{*}$ Values significantly $(p<0.01)$ differ from normal control. ${ }^{*}$ Values significantly $(p<0.05)$ differed from toxic control. ${ }^{* *}$ Values significantly $(p<0.01)$ differed from toxic control. Gr I: normal control; Gr II: toxic control; Gr III: CA (10 mg/kg) $+\mathrm{NaAsO}_{2}(10 \mathrm{mg} / \mathrm{kg})$, Gr IV: CA $(20 \mathrm{mg} / \mathrm{kg})+\mathrm{NaAsO}_{2}(10 \mathrm{mg} / \mathrm{kg})$.
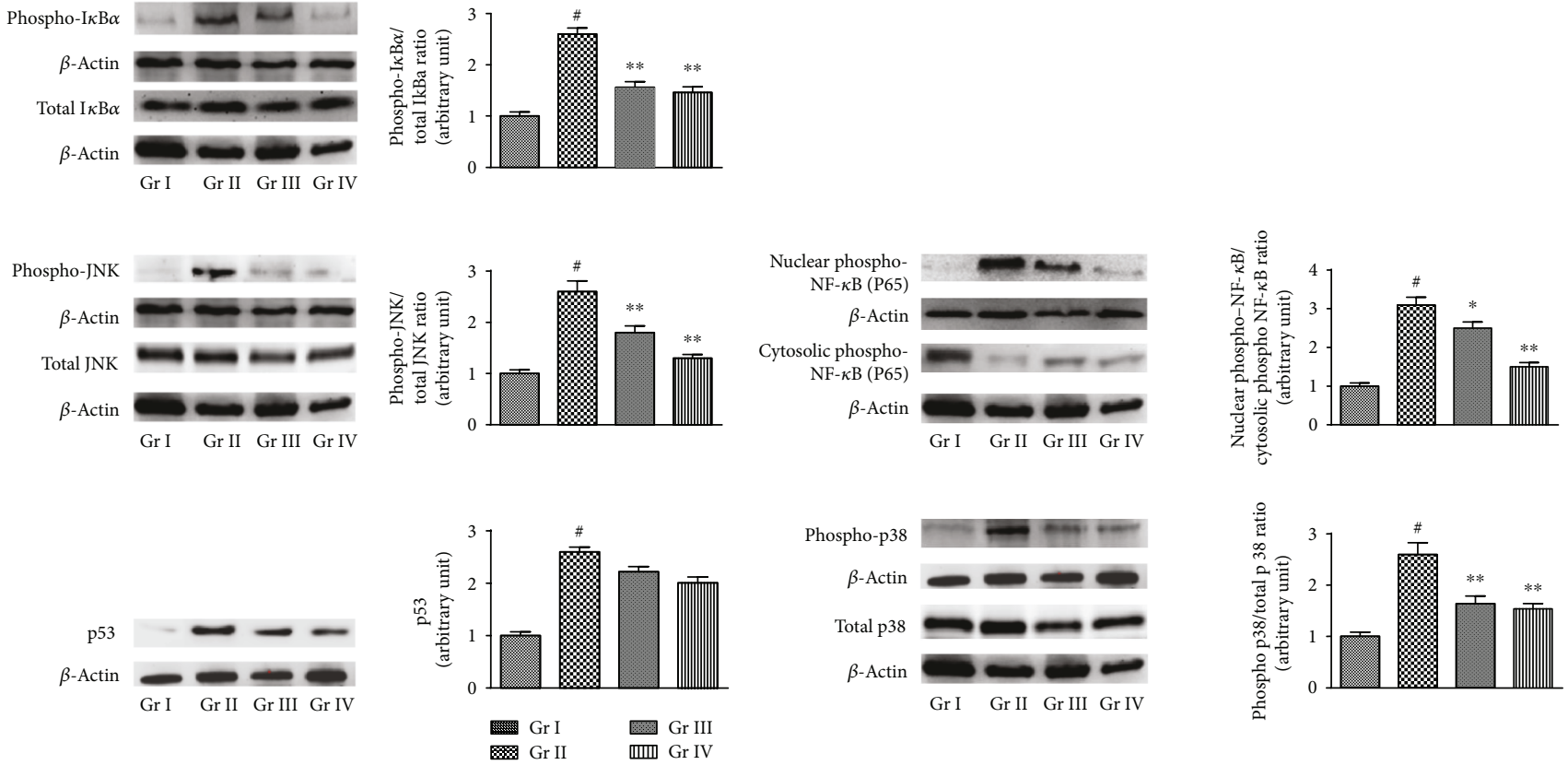

Figure 9: The effect on $\mathrm{I} \kappa \mathrm{Ba}, \mathrm{NF}-\kappa \mathrm{B}$, JNK, p38, and $\mathrm{p} 53$ signaling in the absence $\left(\mathrm{NaAsO}_{2}\right)$ and presence of $\mathrm{CA}\left(\mathrm{NaAsO} \mathrm{O}_{2}+\mathrm{CA}\right)$ in vivo in the liver of experimental mice. The relative band intensities were assessed and the normal control band was allotted a random value of 1 . $\beta$-actin served as loading control. Values are expressed as mean $\pm \operatorname{SD}(n=6) .{ }^{*}$ Values significantly $(p<0.01)$ differ from normal control. *Values significantly $(p<0.05)$ differed from toxic control. ${ }^{* *}$ Values significantly $(p<0.01)$ differed from toxic control. Gr I: normal control; Gr II: toxic control; Gr III: CA $(10 \mathrm{mg} / \mathrm{kg})+\mathrm{NaAsO}_{2}(10 \mathrm{mg} / \mathrm{kg})$, Gr IV: CA $(20 \mathrm{mg} / \mathrm{kg})+\mathrm{NaAsO}_{2}(10 \mathrm{mg} / \mathrm{kg})$. 

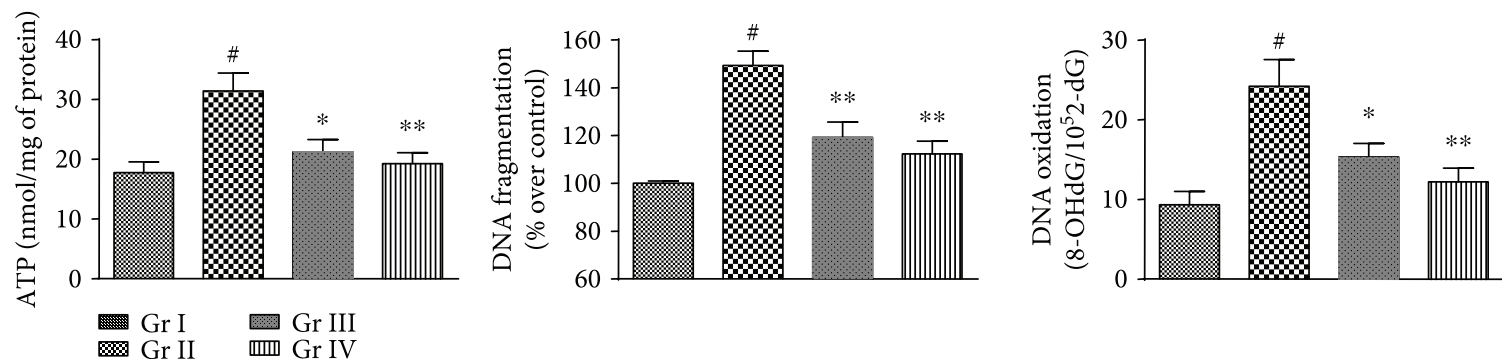

Figure 10: The effect on ATP, DNA fragmentation and DNA oxidation in the absence $\left(\mathrm{NaAsO}_{2}\right)$ and presence of CA $\left(\mathrm{NaAsO} \mathrm{O}_{2}+\mathrm{CA}\right)$ in vivo in the liver of experimental mice. Values are expressed as mean $\pm \mathrm{SD}(n=6) .{ }^{*}$ Values significantly $(p<0.01)$ differ from normal control. ${ }^{*}$ Values significantly $(p<0.05)$ differ from toxic control. ${ }^{* *}$ Values significantly $(p<0.01)$ differ from toxic control. Gr I: normal control; Gr II: toxic control; Gr III: CA $(10 \mathrm{mg} / \mathrm{kg})+\mathrm{NaAsO}_{2}(10 \mathrm{mg} / \mathrm{kg})$, Gr IV: CA $(20 \mathrm{mg} / \mathrm{kg})+\mathrm{NaAsO}_{2}(10 \mathrm{mg} / \mathrm{kg})$.

CA $(10$ and $20 \mathrm{mg} / \mathrm{kg})$ treatment could reinstate $\mathrm{NaAsO}_{2}$ $(10 \mathrm{mg} / \mathrm{kg})$ mediated the aforementioned pathological changes and restored the histology of liver to nearnormal status.

\subsection{In Silico Studies}

3.3.1. ADME Analysis. The drug-likeness and pharmacokinetic properties of CA was evaluated using QikProp module of Schrödinger. Drug-likeness and physicochemical properties were found to be as molecular weight $=332.4, \mathrm{H}$-bond donor $=3, \mathrm{H}$-bond acceptor $=3.5$, predicted water partition coefficient $=3.7$, aqueous solubility $=-4.4$, and total solvent accessible surface area $=575.8$. The pharmacokinetic profiles, such as predicted brain/blood partition coefficient $=-0.7$, predicted apparent Caco-2 cell permeability $=182.7$, number of likely metabolic reactions $=4$, and human oral absorption $=89.3 \%$, are significantly compliant with recommended values of drug-likeness. In Table 3, some other important predicted ADME parameters of CA were presented. The better drug-likeness with acceptable biopharmaceutical properties clearly indicated that CA may be a potential drug candidate.

3.3.2. Molecular Docking. Molecular docking analysis was attempted to dig into the possible binding patterns and interactions of CA with the selective signal proteins. Generated docking poses were ranked on the basis of Glide score. The lowest scored conformer was considered to be the best docking pose. Glide score represents the most capable best fit for a ligand in the active site of the target protein. In this study, Apaf-1 (PDB: 1Z6T), cytochrome C (PDB: 3ZCF), Bid (PDB: 4QVE), Fas (PDB: 3EZQ), and p53 (PDB: 2XWR) did not demonstrate significant docked pose after docking with CA; therefore, these proteins were discarded for further in silico analysis. Hydrogen bond (H-bond) interactions with the catalytic amino acid residues along with Glide score and Emodel values of other proteins were presented in Table 4. Molecular docking of Bax protein with the CA revealed three types of molecular interactions, namely $\mathrm{H}$-bond, cation- $\pi$, and $\pi-\pi$ stacking (Figure 12(a)). It was observed that $\mathrm{H}$-bond interactions are fit into the Bax hydrophobic groove of Leu 122 residue and with the side chain of positively charged Arg 37 residue. The cation- $\pi$ and $\pi-\pi$ stacking interactions were also found with the same charged Arg 37 residue. In case of $\mathrm{Bcl}-2$ protein, no single $\mathrm{H}$-bond interaction was found to be formed with the catalytic residues. However, $\mathrm{H}$-bond was predicted into ligand itself in the presence of $\mathrm{H}_{2} \mathrm{O}$ molecule through intramolecular $\mathrm{H}$-bond interaction (Figure 12(b)). This intramolecular H-bond formation was also highlighted in the cocrystal structure of Bcl-2 (PDB: 4LXD). Docking analysis of caspase 9 revealed that Arg 355 residue participates to form $\mathrm{H}$-bond with $\mathrm{CA}$ along with the formation of $\pi-\pi$ stacking and salt bridge (Figure 12(c)). Since H-bond interaction with Arg 355 was also found with the ligand of X-ray crystal structure of caspase 9 (PDB: 2AR9), therefore, this interaction may be considered as a constraint to play a dynamic role in the biological phenomenon. The binding interactions of caspase 3 revealed that $\mathrm{Thr}$ 62 and Arg 207 residues are involved in H-bond formation with CA (Figure 12(d)). However, Thr 62 residue interacted through $\mathrm{H}_{2} \mathrm{O}$-bridge formation. Caspase 8 was found to interact with two amino acid residues, Glu 396 and Thr 467, to form H-bond interaction with CA (Figure 12(e)). The same Glu 396 residue has been found to participate in H-bond formation in cocrystallized ligand of the PDB (4PRZ).

The binding interactions of $\mathrm{CA}$ with I $\kappa \mathrm{B}$ showed involvement of two residues, backbone atom of Leu 21 and side chain atom of Asp 103 in H-bond formation (Figure 13(a)). When comparing interaction with the cocrystallized structure of $\mathrm{I} \kappa \mathrm{B}$ (PDB: $4 \mathrm{KIK}$ ), it has been found that different amino acid residues (Glu 149, Glu 97, and Cys 99) were involved in $\mathrm{H}$-bond formation. The docking analysis also revealed the predicted interaction for $\mathrm{I} \kappa \mathrm{B}$ with negatively charged Asp 103 residue that might be important for the activation of the receptor. The H-bond interaction with two amino acids, Arg 416 (side chain) and Leu 472 (backbone), was observed between $\mathrm{NF}-\kappa \mathrm{B}$ protein and $\mathrm{CA}$ along with $\pi-\pi$ stacking interaction with Arg 408 residue (Figure 13(b)). The cocrystallized structure of NF$\kappa \mathrm{B}$ (PDB: 4IDV) exhibited that Leu 472 residue is found to participate in $\mathrm{H}$-bond interaction. Docking analysis of JNK exhibited a single $\mathrm{H}$-bond interaction between Asn 114 and CA; however, the crystal structure of JNK (PDB: 4E73) specified the involvement of Met 111 in the interaction (Figure 13(c)). The interaction with Asn 114 might highlight that JNK has 

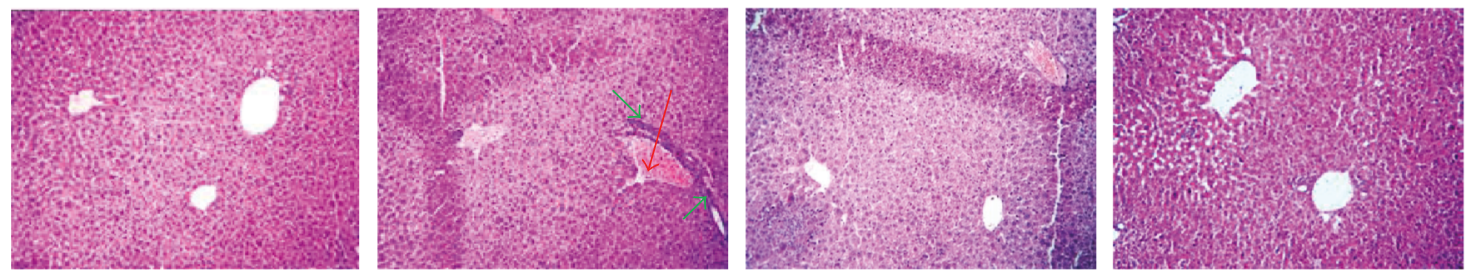

(a)

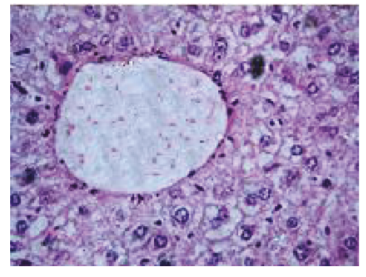

Gr I

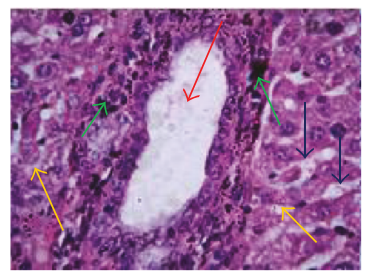

Gr II

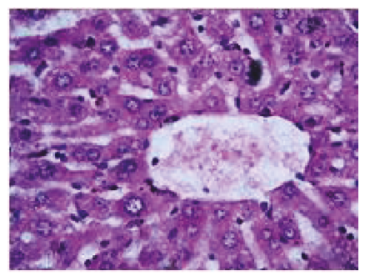

Gr III

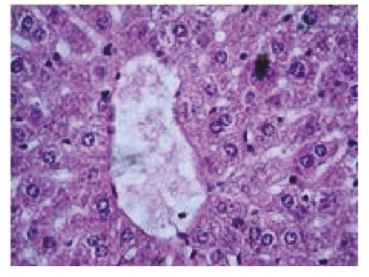

Gr IV

(b)

Figure 11: Histological sections 100x (a) and 400x (b) of the livers of experimental mice in the absence $\left(\mathrm{NaAsO}_{2}\right)$ and presence of CA $\left(\mathrm{NaAsO}_{2}+\mathrm{CA}\right)$. The liver sections of normal mice revealed normal portal vein and hepatocytes. $\mathrm{NaAsO}_{2}$-exposed liver section exhibited dilated portal vein (red arrow), vacuolated cytoplasm (blue arrows), apoptosis (yellow arrows), and leucocytes infiltration (green arrows) when compared with the section of normal control liver. CA treatment could reinstate $\mathrm{NaAsO}_{2}$ mediated the aforementioned pathological changed. Gr I: normal control; Gr II: toxic control; Gr III: CA (10 mg/kg) + NaAsO 2 (10 mg/kg), Gr IV: CA $(20$ mg/kg) + NaAsO 2 (10 mg/kg).

TABle 3: Prediction of drug-likeness and ADME profiles of CA.

\begin{tabular}{lccc}
\hline Sl. number & Descriptors & Predicted values for CA & $\begin{array}{c}\text { Recommended values } \\
\text { (based on properties of 95\% of known drugs) }\end{array}$ \\
\hline 1. & Molecular weight & 332.4 & 130.0 to 725.0 \\
2. & SASA & 575.8 & 300.0 to 1000.0 \\
3. & WPSA & 0.0 & 0.0 to 175.0 \\
4. & H-bond donor & 3.0 & 0.0 to 6.0 \\
5. & H-bond acceptor & 3.5 & 2.0 to 20.0 \\
6. & glob & 0.8 & 0.75 to 0.95 \\
7. & QPlogPo/w & 3.7 & -2.0 to 6.5 \\
8. & QPlogS & -4.4 & -6.5 to 0.5 \\
9. & QPlogHERG & -1.9 & Concern below -5 \\
10. & QPPCaco & 182.7 & 25 poor; $>500$ great \\
11. & QPlogBB & -0.7 & -3.0 to 1.2 \\
12. & QPPMDCK & 100.2 & $<25$ poor, $>500$ great \\
13. & QPlogKp & -3.2 & -8.0 to -1.0 \\
14. & \#metab & 4.0 & 1.0 to 8.0 \\
15. & QPlogKhsa & 0.3 & -1.5 to 1.5 \\
16. & 89.3 & $>80 \%$ is high; $<25 \%$ is poor
\end{tabular}

SASA: total solvent accessible surface area; WPSA: weakly polar component of the SASA; glob: globularity descriptor; QPlogPo/w: predicted octanol/water partition coefficient; QPlogS: predicted aqueous solubility; QPlogHERG: predicted IC Fn value for blockage of HERG K+ channels; QPPCaco: predicted apparent Caco-2 cell permeability; QPlogBB: predicted brain/blood partition coefficient; QPPMDCK: predicted apparent MDCK cell permeability in $\mathrm{nm} / \mathrm{sec}$; QPlogKp: predicted skin permeability; \#metab: number of likely metabolic reactions; QPlogKhsa: prediction of binding to human serum albumin.

another binding site where CA interacted to form $\mathrm{H}$-bond. For the protein $\mathrm{p} 38$, no $\mathrm{H}$-bond interaction was observed but possessed moderate dock score of $-5.608 \mathrm{kcal} / \mathrm{mol}$ in docking. Although, a number of lofty hydrophobic amino acids (Val 38, Ala 51, Val 52, Leu 75, Leu 104, Val 105, Leu 108 , etc.) have been found to interact between CA and p38 (Figure 13(d)).
3.3.3. Molecular Dynamics. The MD simulation was carried out for further refinement and stabilization of the docked complexes in dynamic environment to evaluate the most energetically stable binding conformation. The simulation time range of 20-40 ns was used to allow and permit reorganization of the interaction configuration of protein-ligand complex. In the simulation study, the compactness of each 
TABle 4: Dock score, Emodel value, and interacting residues in molecular docking analysis.

\begin{tabular}{|c|c|c|c|c|c|}
\hline Sl. number & Proteins & $\begin{array}{l}\text { Glide scores } \\
\text { (Kcal/mol) }\end{array}$ & Glide Emodel values & $\begin{array}{l}\text { Interacting residues in } \\
\mathrm{H} \text {-bond interaction }\end{array}$ & Other interactions \\
\hline 1. & Bax & -3.115 & -15.341 & Arg 37, Leu 122 & Cation- $\pi, \pi-\pi$ stacking with Arg 37 \\
\hline 2. & Bcl-2 & -4.986 & -29.586 & - & $\mathrm{H}$-bond with $\mathrm{H}_{2} \mathrm{O}$ \\
\hline 3. & Caspase 9 & -3.596 & -23.725 & Arg 355 & $\pi-\pi$ stacking, salt bridge with Arg 355 \\
\hline 4. & Caspase 3 & -4.263 & -30.352 & Arg 207, Thr 62 & - \\
\hline 5. & Caspase 8 & -4.060 & -19.905 & Glu 396, Thr 467 & - \\
\hline 6. & $\mathrm{I} \kappa \mathrm{B}$ & -6.524 & -33.382 & Asp 103, Leu 21 & - \\
\hline 7. & $\mathrm{NF}-\kappa \mathrm{B}$ & -6.042 & -36.121 & Arg 416, Leu 472 & $\pi-\pi$ stacking with Arg 408 \\
\hline 8. & JNK & -4.642 & -17.079 & Asn 114 & - \\
\hline 9. & p38 & -5.608 & -30.359 & - & - \\
\hline
\end{tabular}

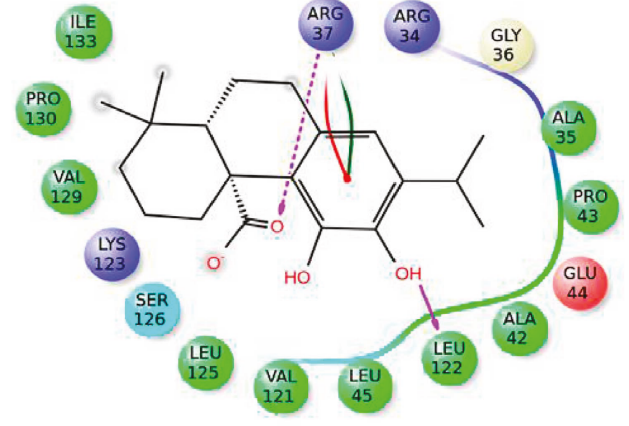

(a)

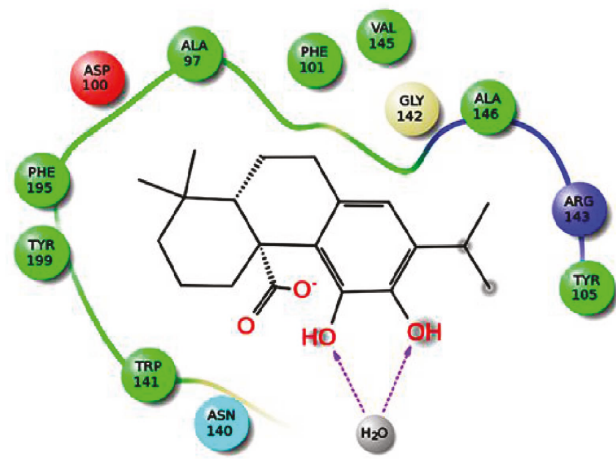

(b)

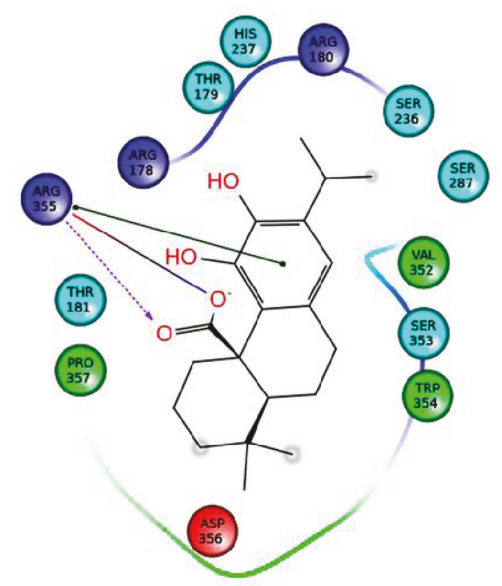

(c)

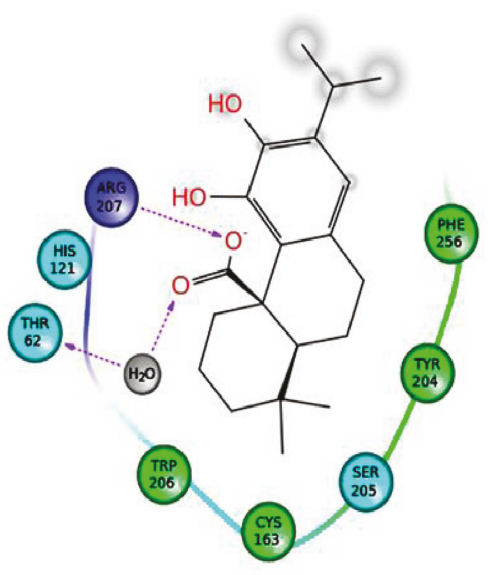

(d)

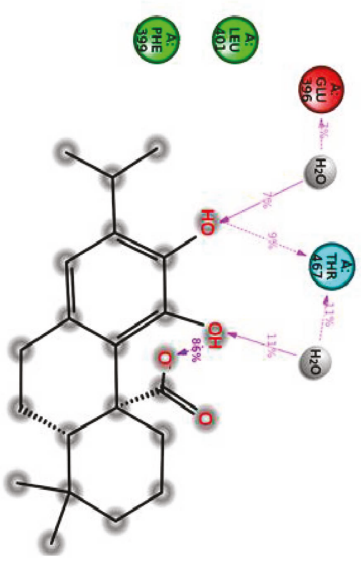

(e)

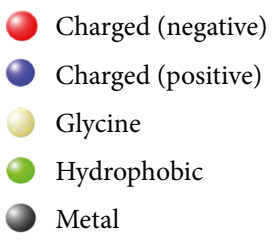
Polar
- Unspecified residue
Water
Hydration site
× Hydration site (displaced)

$$
\begin{aligned}
& \rightarrow \text { Pi-cation } \\
& \text { - Salt bridge } \\
& \text { - Solvent exposure }
\end{aligned}
$$$$
\text { - Metal coordination }
$$$$
\longrightarrow \text { Pi-Pi stacking }
$$

FiguRE 12: Docking interactions of CA with Bax (a), Bcl-2 (b), caspase 9 (c), caspase 3 (d), and caspase 8 (e) proteins.

simulated complex has been analyzed through root-meansquare deviation (RMSD), root-mean-square fluctuation (RMSF), radius of gyration, and the secondary structure elements (SSE) of CA ligand interactions with the selective protein along with stable $\mathrm{H}$-bond and hydrophobic interactions. The RMSD plot of Bax-CA complex showed that there 


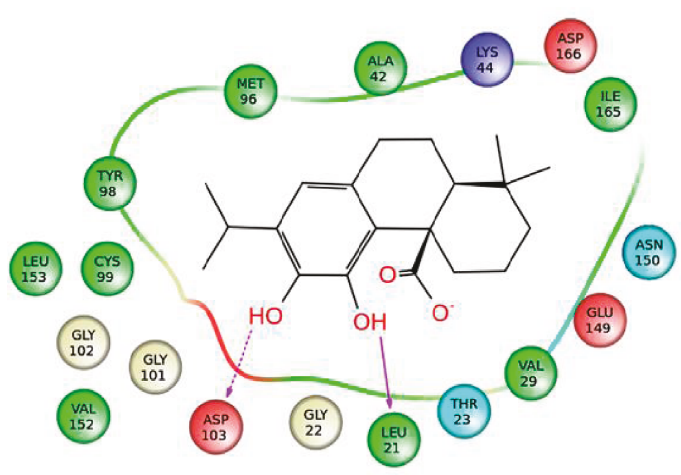

(a)

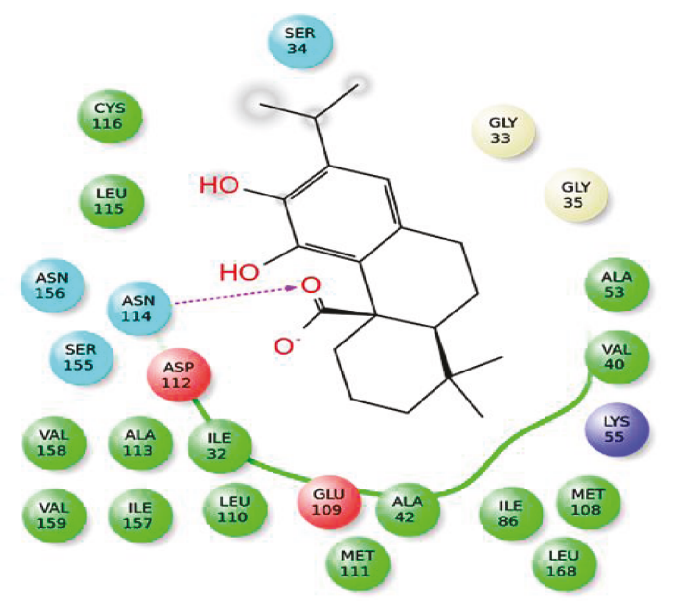

(c)

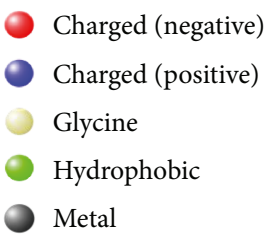

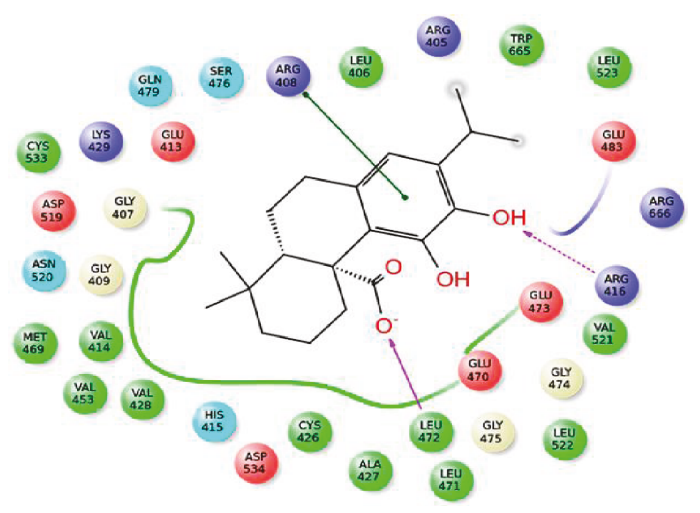

(b)

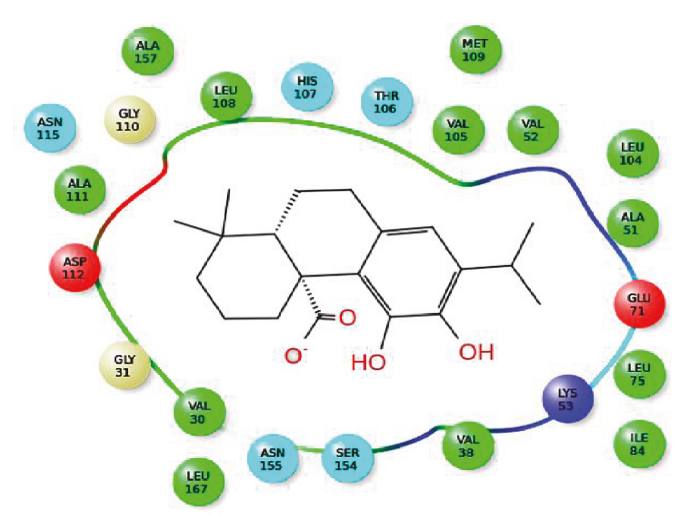

(d)

$$
\begin{aligned}
& \text { - Pi-cation } \\
& \text { - Salt bridge } \\
& \text { - Solvent exposure }
\end{aligned}
$$$$
\text { - Metal coordination }
$$$$
\bullet \text { Pi-Pi stacking }
$$

Figure 13: Docking interactions of CA with I $\kappa$ B (a), NF- $\kappa$ B (b), JNK (c), and p38 (d) proteins.

is significant deviation till $30 \mathrm{~ns}$ of run. However, the complex was thereafter found to be appropriately stable and consistent until reaching to the end of the run (Figure 14(a)). The modeling analysis clearly appeared that the regions comprising catalytic amino acids of Bax protein interacting with CA exhibited adequate conformational stabilities. During the simulation run of Bcl-2-CA complex, the dynamic nature of interaction has been witnessed at $20 \mathrm{~ns}$. The proteinligand RMSD plot for Bcl-2-CA complex showed equilibrated simulation complex and stabilized at RMSD value of around $3 \AA$ for protein backbone (Figure 14(b)). However, when the protein-ligand complex was first aligned on the protein backbone, the rearrangement of conformation explained a high deviation in RMSD of ligand with respect to time. Analysis of MD features of caspase 9-CA complex revealed the RMSD plot of MD complex with high fluctuation at the initial stage; however, after $32 \mathrm{~ns}$, the complex become stabilizes gradually (Figure 14(c)). Analysis of the protein SSE, it has been noticed that a total of around $40.74 \%$ SSE contributed to the overall protein stability for caspase 9-CA complex. To realize the behavior of caspase 3-CA complex in dynamic environment, the MD simulation was carried out at $40 \mathrm{~ns}$ to study the molecular interaction pattern of the simulated complex. It has been observed in the RMSD plot (Figure 14(d)) that most stable time period for caspase 3-CA complex is $30-40$ ns of the simulation run. For the production of binding orientation of caspase 8-CA complex in MD-simulated state, the simulation was 


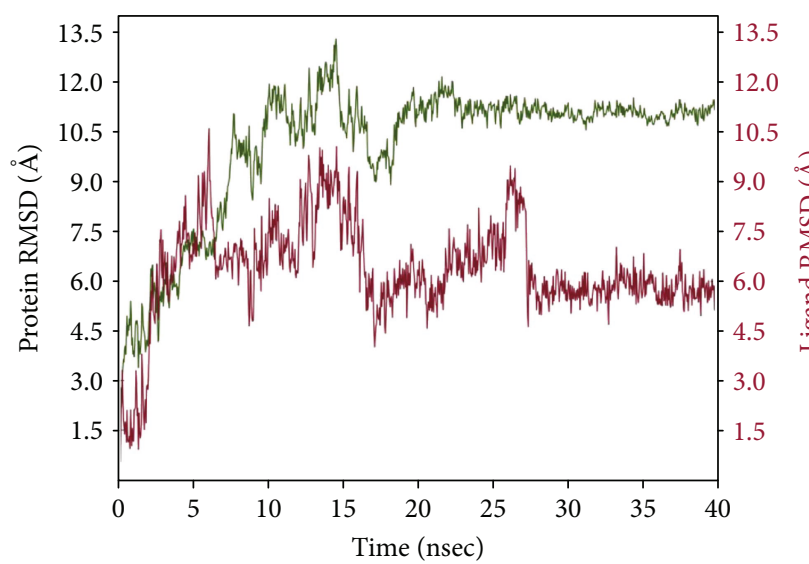

Backbone

(Lig) fit on Port

(a)

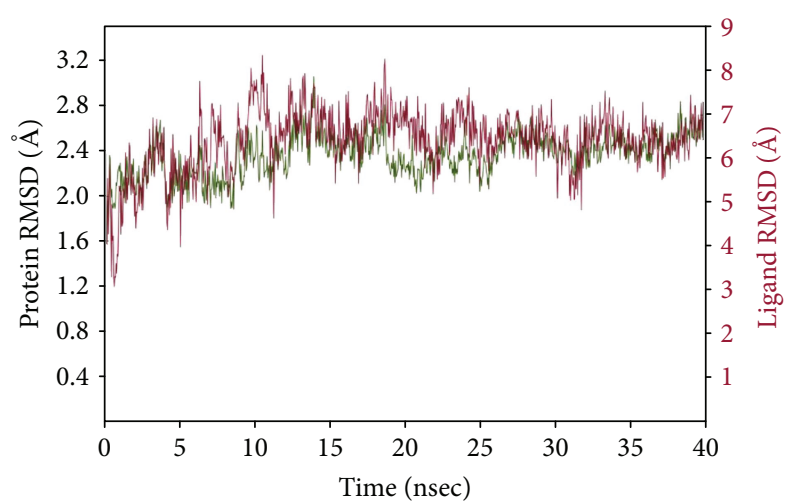

Backbone

(Lig) fit on Port

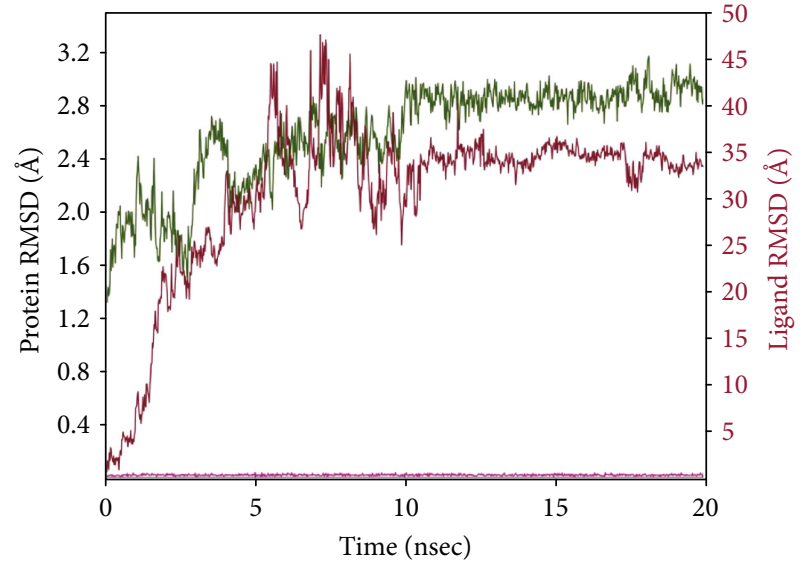

Backbone

(Lig) fit on Port

(b)

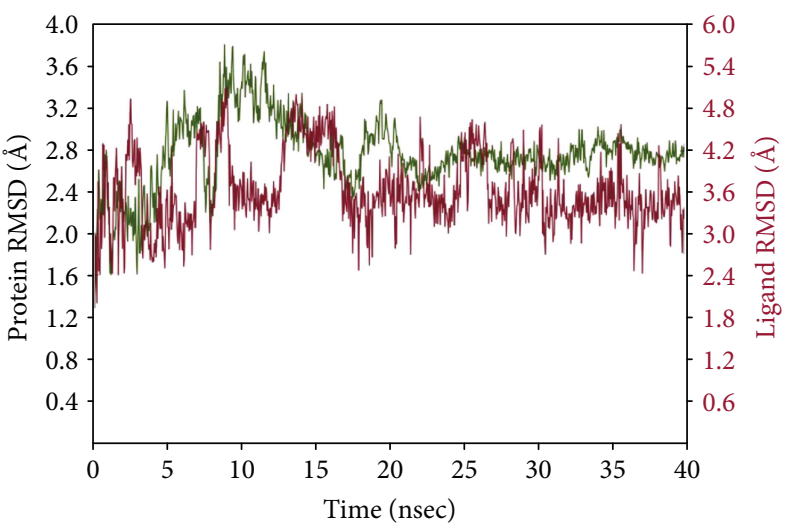

Backbone

(Lig) fit on Port

(c)

(d)

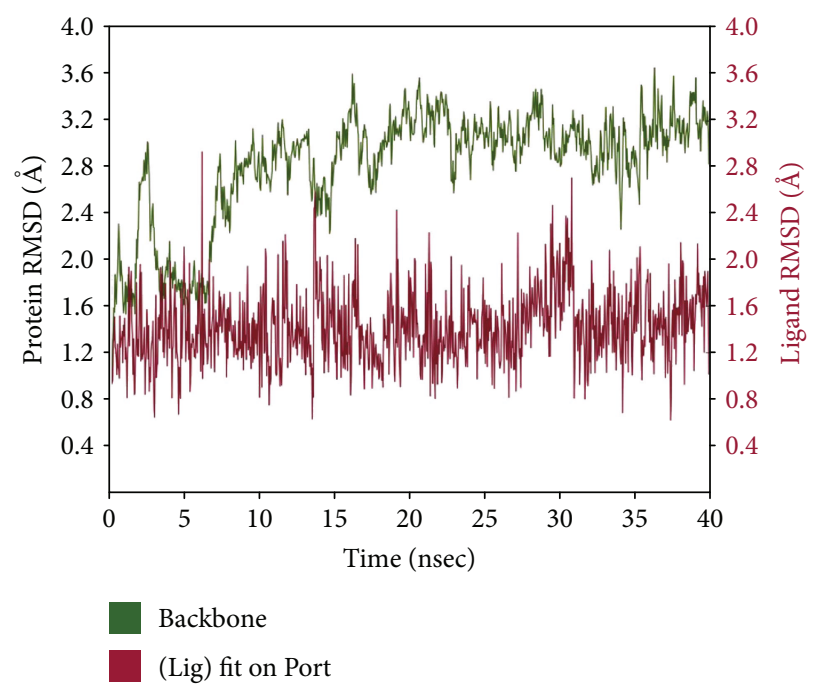

(e)

Figure 14: MD-simulated RMSD plot of Bax (a), Bcl-2 (b), caspase 9 (c), caspase 3 (d), and caspase 8 (e) backbones and CA ligand complex. 


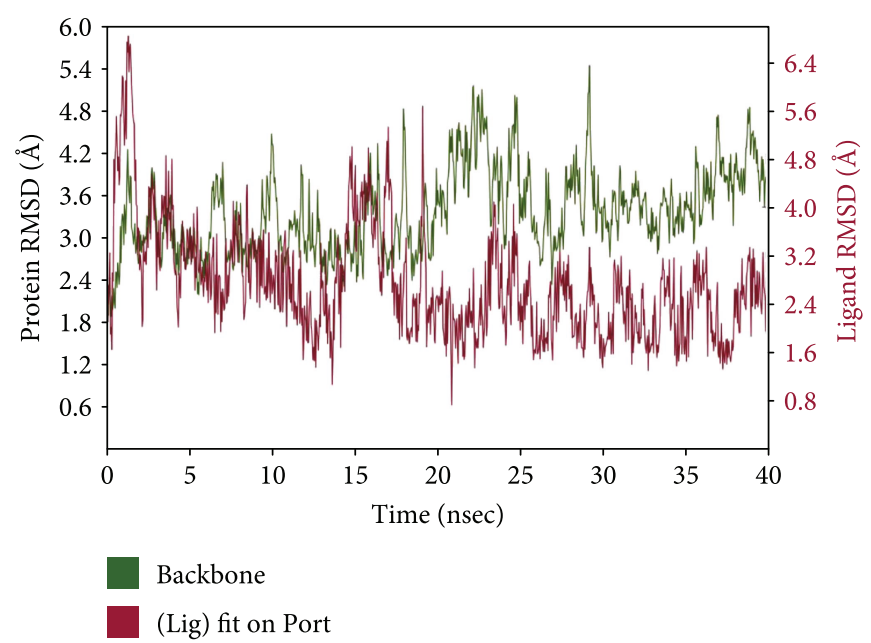

(a)

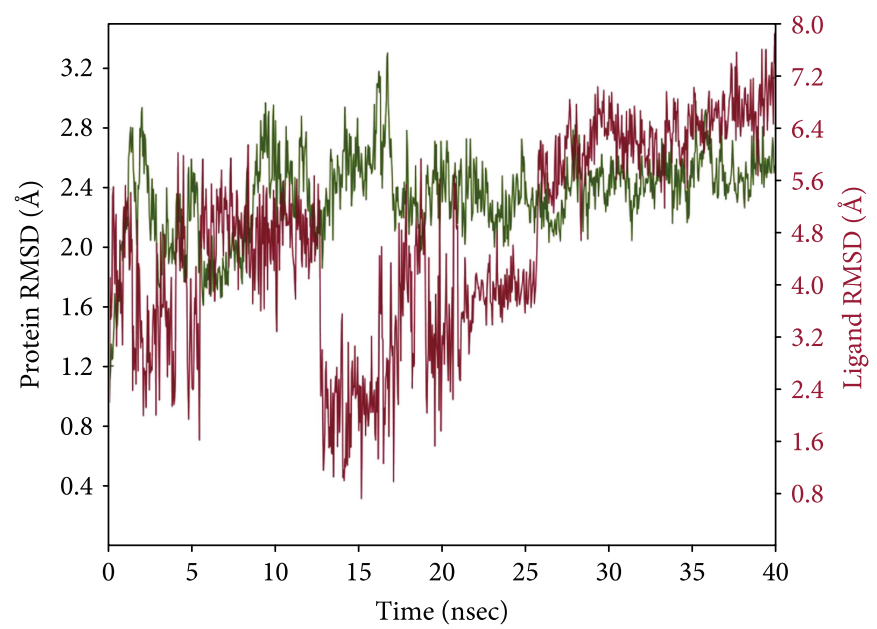

Backbone

(Lig) fit on Port

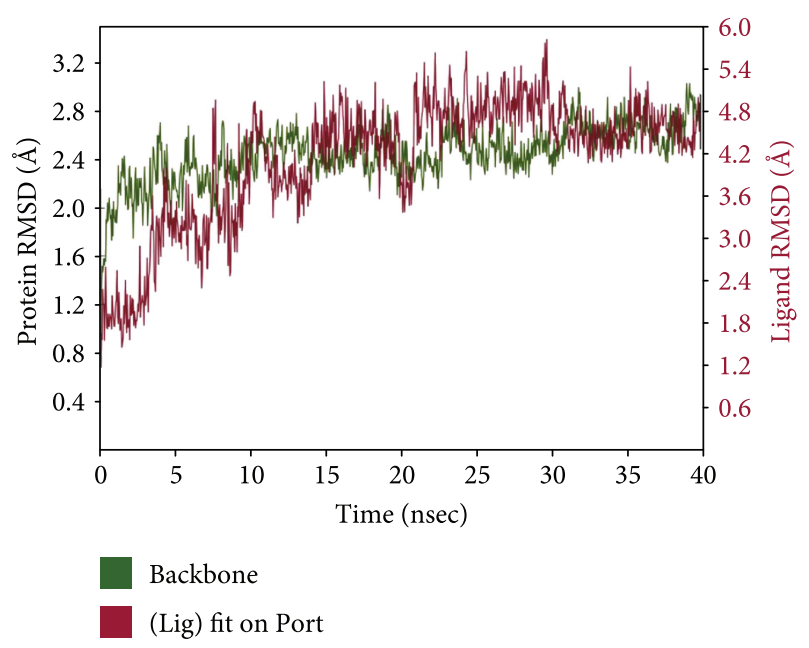

(b)

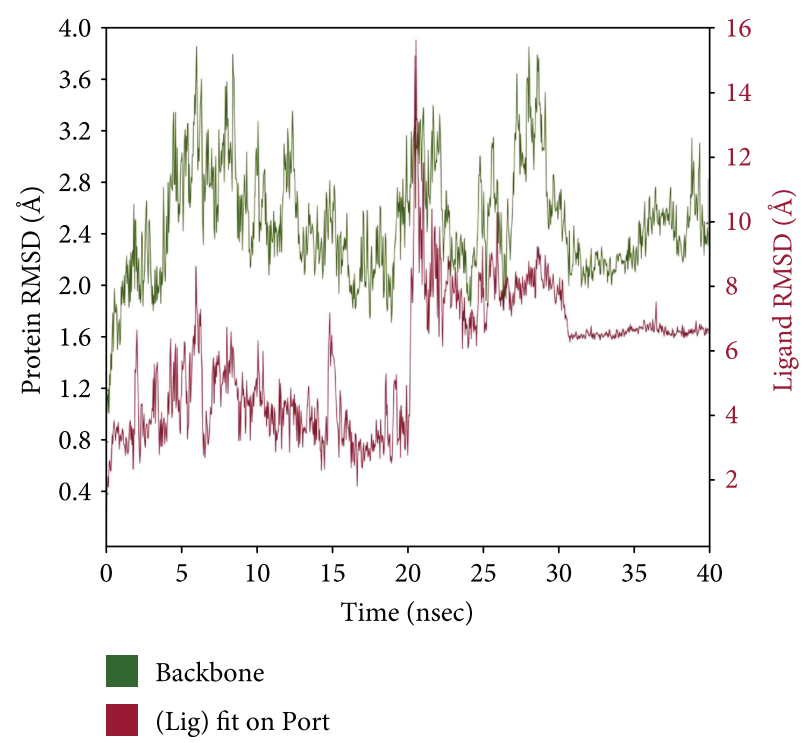

(d)

Figure 15: MD-simulated RMSD plot of I $\kappa \mathrm{B}(\mathrm{a}), \mathrm{NF}-\kappa \mathrm{B}(\mathrm{b})$, JNK (c), and p38 (d) backbones and CA ligand complex.

executed at $40 \mathrm{~ns}$. It has been noted that the complex is sufficiently stable in the long run (7-40 ns). It was exhibited by RMSDs of about 3.2 and $2.0 \AA$ for protein backbone and ligand, respectively (Figure 14(e)). The MD simulation of I $\kappa \mathrm{B}-\mathrm{CA}$ ligand bound complex was performed up to $40 \mathrm{~ns}$. The RMSD plot (Figure 15(a)) showed minimal fluctuations during simulation run; however, a consistent interaction has been observed across the MD simulation trajectory after $25 \mathrm{~ns}$. In protein SSE, $\alpha$-helices (45.15\%) and $\beta$-strands (7.41\%) were monitored throughout the simulation. An interaction pattern at different time points of $\mathrm{MD}$ simulation for NF- $\kappa \mathrm{B}$ and CA complex has been recorded for $40 \mathrm{~ns}$ (Figure 15(b)). Although fluctuation in the RMSDs plot has been observed up to $30 \mathrm{~ns}$ of run, but the fluctuation was reduced during the run at 30-40 ns. It suggested that complex is undergoing a large conformational change and it leads to the equilibrated state during the simulation. The MD simulation run at $40 \mathrm{~ns}$ for the JNK-CA complex has not shown the consistent interaction across the MD simulation trajectory, as depicted in RMSD plot (Figure 15(c)). To evaluate the dynamic stability of p38-CA complex subjected to MD simulation for $40 \mathrm{~ns}$, the RMSD plot showed higher congeneric fluctuation followed by small and large peaks in between (Figure 15(d)). The fluctuation-differentiate extended throughout the conformational arrangement as supported by docked complex which has not generated any bond interaction.

\section{Discussion}

Arsenites-contaminated drinking water has been regarded as a major hazard over 70 countries in the world [4]. Inorganic arsenicals have been shown to induce cytotoxic effect to the various organs through generation of excess of intracellular ROS coupled with downregulation of endogenous redox defense [4]. Therefore, employing an antioxidant would be 
a therapeutic strategy to counteract with As-mediated toxic exhibitions. CA, a naturally occurring phenolic diterpene, has been reported to possess significant ROS scavenging and antioxidant activities $[14,15]$. It is one of the antioxidant food additives. Dried rosemary is used as a food component in various recipes. Dried rosemary (0.4-2.5 g/serving) corresponds to $0.05-0.4 \mathrm{mg} / \mathrm{kg}$ of CA [37]. Rosemary extract $(0.01-2 \mathrm{~g} / \mathrm{kg})$ is also used as flavouring in processed foods. Rosemary extract containing variable amount of CA (5-20\%) was classified as a food additive by the European Commission [37, 38]. Through various rosemary supplements up to $1-2 \mathrm{mg} / \mathrm{kg}$ of CA is consumed by human per day [37].

Present studies have been executed to evaluate the probable prophylactic role of CA against As intoxication in the liver of experimental mice employing established in vitro and in vivo preclinical assays. Despite the mouse has a higher metabolic turnover than human, the mouse has similar metabolite profile as human adults [39]. The absorption, distribution, and excretion of trivalent As follow similar patterns in both mouse and human. Trivalent As follow similar metabolic pattern like arsenite $\rightarrow$ monomethylarsonate $\rightarrow$ dimethylarsenite in both human and mouse [40]. Besides, As-mediated dysfunction in hepatic endothelial cells follows similar redox signaling in both mouse and human [41]. Considering the association in phenotypic anchors namely adsorption, arsenic burden in tissues, metabolism, excretion, and altered gene expression between the Asexposed human and mouse [41], mouse model has been employed in this study.

Haematological and serum biochemical status give primary indications of toxicological proceedings within the body and/or in the precise organs. In this study, $\mathrm{NaAsO}_{2}$ exposure significantly reduced erythrocyte count and thereby exhibited a significant reduction in haemoglobin level in mice. As-induced oxidative haematotoxicity has been reported in earlier literatures [6, 42]. As experiences biotransformation in the hepatic tissues through binding with thiol group of proteins and thereby interferes with the integrity of the membrane of hepatocytes following leakage of AST and ALT into the sera [6]. Therefore, AST and ALT are accepted to be the markers for hepatotoxicity [6]. In this study, significant raise in the AST and ALT levels was observed in the sera of $\mathrm{NaAsO}_{2}$-exposed mice. Similarly, the high levels of $\mathrm{LDH}$ and $\mathrm{CK}$ in the sera confirmed the loss of membrane integrity due to $\mathrm{NaAsO}_{2}$ intoxication. The high levels of aforementioned tissue-specific enzymes confirmed the induction of hepatotoxicity by $\mathrm{NaAsO}_{2}$. On the other hand, CA treatment could significantly reinstate the levels of aforementioned tissue-specific enzymes in the sera, which primarily gave an impression of hepatoprotective effect of the compound.

The earlier explanations revealed that $\mathrm{NaAsO}_{2}$ exposure significantly promoted intracellular ROS generation in both in vitro and in vivo systems $[7,15,43]$. ROS have multiple targets to initiate and propagate toxicological events namely oxidative destruction of cellular macromolecules, assuaging the endogenous redox defense and endorsing the apoptotic event via transformation in the normal transcriptions of different signaling proteins [26]. In this study, $\mathrm{NaAsO}_{2}$ exposure caused significant production and accumulation of intracellular ROS, which finally exerted significant extent of cytotoxic effect. The ROS in excess directly expose peroxidative injury to the membrane lipids, carbonylation of cellular proteins, and oxidation of nucleic acids [21]. However, CA could significantly attenuate the ROS-mediated toxicosis to the cellular biomolecules. The experimental observation would be correlated to the restriction of ROS production and/or ROS scavenging effect by CA.

Cellular redox defense systems play an imperative role to neutralize oxidative stress [44]. Cellular antioxidant enzymes and GSH constitute endogenous redox defense reservoir [44]. $\mathrm{NaAsO}_{2}$ exposure further endorse redox stress through significant inhibition of endogenous redox defense systems, which was in accordance to the previous observations $[1,6,7]$. Decrease in the levels of SOD and CAT could be accounted to an overproduction of superoxide anion during As metabolism [45]. Arsenites have high affinity toward thiol group [46], which would be corroborated to the depletion of cellular GSH levels. GSH acts as the substrate for the enzymes, specifically GR, GPx, and GST. The downregulation in the activities of GR, GPx, and GST would be correlated to the strong affinity of arsenites toward thiol group. Besides, GSH is also known to be a key intracellular reductant for As methylation and transport and thereby facilitate the removal of As from the body [47]. GSH-As complexes act as substrates for the ATP-binding cassette membrane transporters, which facilitate active efflux of As from the cells [48]. Depletion of hepatic GSH helps accumulation of As in the liver and promotes oxidative stress. On the other hand, CA along with $\mathrm{NaAsO}_{2}$ could significantly improve the cellular redox defense via augmenting the levels of endogenous antioxidant enzymes and GSH. CA treatment also promoted As clearance from hepatic tissue, which would be correlated with the CA-mediated upregulation of hepatic GSH level. The probable mechanism of CA has been proposed to be the conversion of catechol type-CA to quinone type-CA through donation of a pair of electrons to oxygen radicals to become electrophilic [49]. This quinone type-CA has been reported to form adducts with the -SH of GSH and/or other protein/enzymes and thereby activate antioxidant-responsive element. This antioxidant-responsive element further induces phase 2 enzymes and increases GSH level [49].

ROS has been reported to endorse apoptosis via alteration in the expressions of different signal proteins from their normal transcriptional levels [26]. ATP supplies the required energy for this programmed cell death [26]. In this study, a significantly high level of cytosolic ATP in the hepatic tissue followed by $\mathrm{NaAsO}_{2}$ exposure revealed the favorable cellular atmosphere for the cleavages of caspases in the cytosol. The augmentation of cytosolic ATP may be correlated to that of $\mathrm{NaAsO}_{2}$-mediated downregulation of microsomal ATPases in the liver [50]. Apoptosis is usually governed by the complex reciprocity between the pro- and antiapoptotic events via the transcription of respective signal proteins. $\mathrm{Bax}$ is a proapoptotic member of Bcl-2 family, which regulates apoptosis through mitochondrial stress. Translocation 
of Bax protein into mitochondria from cytosol initiates intrinsic apoptotic signaling [51]. In this study, $\mathrm{NaAsO}_{2}$ intoxication caused activation of proapoptotic signaling and mitigation, which was apparent from significant upregulation of Bax protein in mitochondria. Besides, $\mathrm{NaAsO}_{2}$ could significantly inhibit the expression of Bcl-2 in cytosol, which is a member of antiapoptotic protein [21]. The Bax translocation further opens the transition pores in the mitochondrial membranes resulting with the release of cytochrome $\mathrm{C}$ into the cytosol [26]. Cytochrome $\mathrm{C}$ release would be further potentiated through the downregulation of Bcl-2 in the cytosol [52]. In this study, a significant upregulation in the expression of cytochrome $\mathrm{C}$ in the cytosol was observed in $\mathrm{NaAsO}_{2}$-exposed hepatic cells. The release of cytochrome $\mathrm{C}$ into cytosol provides a key signal for the intrinsic pathway of apoptosis [52]. Through the interaction with Apaf-1, cytochrome $\mathrm{C}$ potentiates the downstream apoptotic signaling cascades via cleavages of caspases 9 and 3 into their respective cleaved/active forms in cytosol [52, 53]. It has been regarded that cytochrome $\mathrm{C}$ release is distal to caspase 8 activation in Fas-mediated apoptosis [52]. Earlier investigation revealed that, ROS can potentiate the death-receptor mediated apoptosis through receptor clustering and establishment of lipid raft-derived signaling platforms [54]. The Fas signaling is one of the key processes in extrinsic/death receptor-mediated apoptosis. In the extrinsic pathway of apoptosis, the activation of FAS resulted in the cleavage of procaspase 8 into its cleaved/active form followed by activation of Bid signaling [55]. In this study, significant upregulation in the expressions of FAS, cleaved caspase 8 , and Bid were observed in $\mathrm{NaAsO}_{2}-$ exposed hepatic cells. CA treatment could significantly attenuate the intrinsic and extrinsic pathways of apoptosis via reciprocating the expression of the involved transcription factors except Bid. NF- $\kappa B$ is one of the redox-sensitive transcription proteins. ROS significantly contributes in signaltransduction pathways of NF- $\kappa \mathrm{B}$ [21]. The NF- $\kappa \mathrm{B}$ signaling is initiated with the phosphorylation of $\mathrm{I} \kappa \mathrm{B} \alpha$ on Ser 32 followed by translocation of phospho-NF- $\kappa \mathrm{B}$ (Ser 536) to the nucleus [56]. Nuclear translocation of phospho-NF- $\kappa \mathrm{B}$ can trigger proapoptotic event via promotion of Bax translocation to mitochondria. NF- $\kappa \mathrm{B}$ can also potentiate the expression of Fas-ligand and thereby exert a proapoptotic role [57]. In this study, $\mathrm{NaAsO}_{2}$ significantly upregulated NF-kB signaling and that could be attenuated by CA treatment. Among the many signaling pathways, mitogenactivated protein kinase (MAPK) family proteins are crucial for the maintenance of cells. C-Jun N-terminal kinase (JNK) and p38 are stress responsive signal proteins involved in apoptosis [58]. MAPK member proteins are also redox sensitive [21]. Strong functional interactions exist between the p53 and MAPK [59]. The activation of p53 can lead to cell cycle arrest [60]. Earlier observation revealed that, p38, JNK, and p53 significantly contribute in arsenite-induced apoptosis via activation of proapoptotic signaling in the mitochondria $[60,61]$. In this study, significant upregulation in the p38, JNK, and p53 signaling was observed in $\mathrm{NaAsO}_{2}$ exposed hepatic cells. CA could significantly attenuate $\mathrm{NaAsO}_{2}$-mediated p38 and JNK signaling via preventing their phosphorylation. However, CA did not show significant control on p53 signaling in the hepatic cells of mice. Experimental observation revealed that CA exerted antiapoptotic effect through inhibition of MAPK activation, imbalance of pro- and antiapoptotic factors, and inhibition of caspase cleavage.

Utilizing chemometric analysis, valuable information on molecular basis has been elucidated for different proteinligand complex structures in silico. In this study, Bax, Bcl-2, caspase 9 , caspase 3 , caspase $8, \mathrm{I} \kappa \mathrm{B}, \mathrm{NF}-\kappa \mathrm{B}$, JNK, and $\mathrm{p} 38$ demonstrated significant interactions with $\mathrm{CA}$ in silico, which were in accordance to our observation in in vitro and in vivo studies. On the other hand, Apaf-1, cytochrome C, Bid, Fas, and p53 did not demonstrate significant docked pose. In our experiment, we did not observe any effect of $\mathrm{CA}$ on Bid and p53 expressions. However, CA has been found to regulate the expressions of Apaf-1, cytochrome C, and $\mathrm{Fas}$ in vitro and in vivo. The $\mathrm{H}$-bond formation which is a key interaction to explicate the stability of the CA inside the binding pocket has been observed for most of the proteins, except Bcl- 2 and p38. The $\pi-\pi$ stacking, a noncovalent interaction, has been observed with Bax, caspase 9, and NF- $\kappa \mathrm{B}$ proteins. It might play vital roles in stabilization of protein structures and therefore important in many aspects of macromolecular study. The $\pi-\pi$ stacking arrangement has been previously observed in many protein crystal structures as this arrangement is conserved in some families of enzymes. The occurrence of cation- $\pi$ interaction, another type of noncovalent bonding, has been identified with positively charged residue in Bax protein. This interaction has been regarded as the most important interaction in structural biology. It plays a vital role in molecular recognition and signaling. MD simulations for all the complexes indicate that most interactions appeared in docking analysis are stable during $\mathrm{MD}$ simulation except JNK and p38. Thus, CA may be considered as a potential drug candidate having a wide range of bioactivity and may provide multitherapeutic benefits.

\section{Conclusion}

$\mathrm{NaAsO}_{2}$-mediated production and accumulation of oxidative free radicals play significant role in the As-induced hepatotoxicity. The present study demonstrated that $\mathrm{NaAsO}_{2}$ can elicit hepatocellular apoptosis by triggering $\mathrm{NF}-\kappa \mathrm{B}, \mathrm{MAPK}, \mathrm{p} 53$, and intrinsic and extrinsic apoptotic signaling. On the other hand, treatment with the CA could significantly attenuate $\mathrm{NaAsO}_{2}$-mediated hepatotoxicity by counteracting with oxidative stress, promoting endogenous redox defense, accelerating As clearance and downstream regulation of apoptotic signaling cascades as observed in in vitro and in vivo preclinical assays (Figure 16). In silico molecular docking studies predicted the possible interactions between $\mathrm{CA}$ and the active sites of signal proteins. In silico ADME prediction revealed that CA supports the drug-likeness character ostensible from Lipinski's rule of five. Therefore, CA would have a good possibility to be a new therapeutic agent to counteract with As-mediated toxic manifestations. 


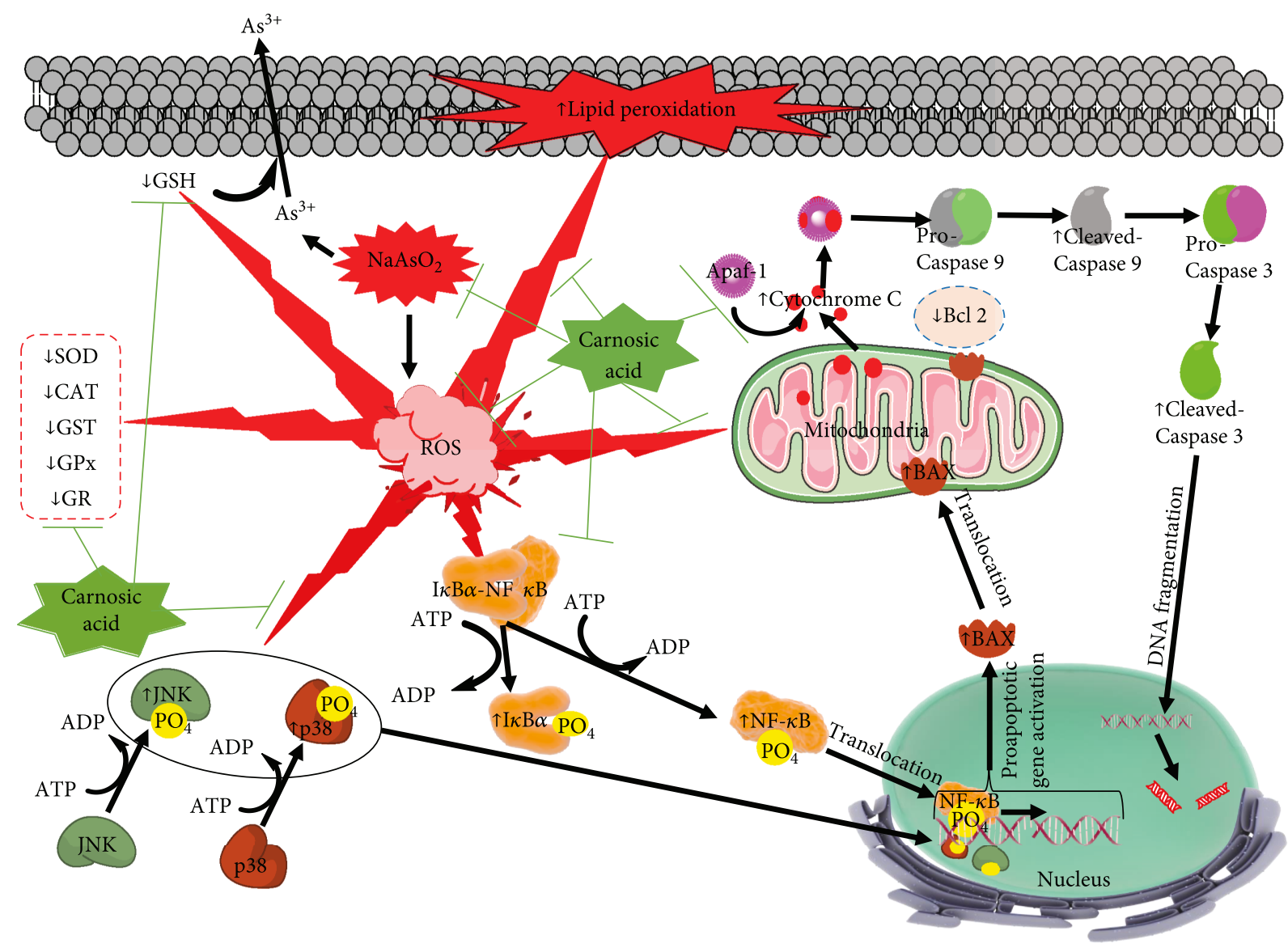

FIGURE 16: Schematic presentation probable protective mechanism of CA against $\mathrm{NaAsO}_{2}$-mediated hepatic injury. The red lightning bolts indicated the pathological events involved within $\mathrm{NaAsO}_{2}$-exposed hepatic cells. The green lines denoted the activity restricted by CA.

\section{Conflicts of Interest}

The authors declare that there is no conflict of interests.

\section{Authors' Contributions}

Saikat Dewanjee, Prasenjit Manna, Supratim Ray, and Vincenzo De Feo designed the experiments. Saikat Dewanjee and Prasenjit Manna supervised the work. Swarnalata Joardar, Prasenjit Manna, and Jatin Kalita performed in vitro assays. Niloy Bhattacharjee performed flow cytometric analysis and image assay. Sonjit Das, Tarun K. Dua, Swarnalata Joardar, and Ritu Khanra performed in vivo assay. Sonjit Das and Swarnalata Joardar performed immunoblot analysis for in vivo assay. Shovonlal Bhowmick, Supratim Ray, and Achintya Saha performed in silico analysis. Saikat Dewanjee and Prasenjit Manna compiled and analyzed the data. Saikat Dewanjee, Prasenjit Manna, and Vincenzo De Feo wrote the manuscript. Sonjit Das and Swarnalata Joardar contributed equally to this work.

\section{Acknowledgments}

The authors gratefully acknowledge the University Grants Commission (UGC), New Delhi, India, for providing the Rajiv
Gandhi National Fellowship (Ref. no. F1-17.1/2013-14/RJNF2013-14-SC-ASS-52029 (SA-III/Website) dated 06.02.3014) to Mister Sonjit Das. The authors are thankful to the Department of Biotechnology (DBT), Ministry of Science and Technology, Government of India, for providing the Ramalingaswami Re-Entry Fellowship (Grant no. BT/RLF/ Re-Entry/34/2013) to Dr. Prasenjit Manna. The authors are thankful to Jadavpur University, Kolkata, India, and the Director, CSIR-NEIST for providing necessary facilities for this study. The authors are thankful to Ms. Cassandra Warden, Vanderbilt University Medical Center, Department of Ophthalmology, USA, for excellent editing of this manuscript.

\section{Supplementary Materials}

Supplementary Figure 1: effect of $\mathrm{NaAsO}_{2}$ at different concentrations on cell viability in isolated murine hepatocytes. Values are expressed as mean \pm SD $(n=3)$. Supplementary Figure 2: effect of CA to the histological structure of livers of experimental mice. Supplementary Table 1: the effect of CA $(4 \mu \mathrm{M})$ on ROS accumulation, lipid peroxidation, protein carbonylation, and endogenous redox systems in isolated murine hepatocytes. Supplementary Table 2: effects of CA (10 and $20 \mathrm{mg} / \mathrm{kg}$ ) on haematological, serum biochemical, and redox parameters in mice. (Supplementary Materials) 


\section{References}

[1] A. K. Das, S. Bag, R. Sahu et al., "Protective effect of Corchorus olitorius leaves on sodium arsenite-induced toxicity in experimental rats," Food and Chemical Toxicology, vol. 48, no. 1, pp. 326-335, 2010.

[2] P. Roy and A. Saha, "Metabolism and toxicity of arsenic: a human carcinogen," Current Science, vol. 82, no. 1, pp. 38-45, 2002.

[3] R. N. Ratnaike, "Acute and chronic arsenic toxicity," Postgraduate Medical Journal, vol. 79, no. 933, pp. 391-396, 2003.

[4] A. K. Das, S. Dewanjee, R. Sahu, T. K. Dua, M. Gangopadhyay, and M. K. Sinha, "Protective effect of Corchorus olitorius leaves against arsenic-induced oxidative stress in rat brain," Environmental Toxicology and Pharmacology, vol. 29, no. 1, pp. 64-69, 2010.

[5] A. K. Das, R. Sahu, T. K. Dua et al., "Arsenic-induced myocardial injury: protective role of Corchorus olitorius leaves," Food and Chemical Toxicology, vol. 48, no. 5, pp. 1210-1217, 2010.

[6] T. K. Dua, S. Dewanjee, M. Gangopadhyay, R. Khanra, M. Zia-Ul-Haq, and V. De Feo, "Ameliorative effect of water spinach, Ipomea aquatica(Convolvulaceae), against experimentally induced arsenic toxicity," Journal of Translational Medicine, vol. 13, no. 1, p. 81, 2015.

[7] T. K. Dua, S. Dewanjee, and R. Khanra, "Prophylactic role of Enhydra fluctuans against arsenic-induced hepatotoxicity via antiapoptotic and antioxidant mechanisms," Redox Report, vol. 21, no. 4, pp. 147-154, 2016.

[8] J. J. Stevens, B. Graham, A. M. Walker, P. B. Tchounwou, and C. Rogers, "The effects of arsenic trioxide on DNA synthesis and genotoxicity in human colon cancer cells," International Journal of Environmental Research and Public Health, vol. 7, no. 5, pp. 2018-2032, 2010.

[9] L. Li, P. Qiu, B. Chen et al., "Reactive oxygen species contribute to arsenic-induced EZH2 phosphorylation in human bronchial epithelial cells and lung cancer cells," Toxicology and Applied Pharmacology, vol. 276, no. 3, pp. 165-170, 2014.

[10] K. Jomova, Z. Jenisova, M. Feszterova et al., "Arsenic: toxicity, oxidative stress and human disease," Journal of Applied Toxicology, vol. 31, no. 2, pp. 95-107, 2011.

[11] T. Rossman, "Arsenic," in Environmental and Occupational Medicine, W. Rom and S. Markowitz, Eds., pp. 1006-1017, Lippincott Williams \& Wilkins, Hagerstown, MD, 4th edition, 2007.

[12] K. Schwarz and W. Ternes, "Antioxidative constituents of Rosmarinus officinalis and Salvia officinalis," Zeitschrift für Lebensmittel-Untersuchung und Forschung, vol. 195, no. 2, pp. 99-103, 1992.

[13] S. Manoharan, S. Balakrishnan, V. Vinothkumar, and S. Silvan, "Anti-clastogenic potential of carnosic acid against 7, 12-dimethylbenz (a) anthracene (DMBA) -induced clastogenesis," Pharmacological Reports, vol. 62, no. 6, pp. 1170-1177, 2010.

[14] A. I. Kuzmenko, R. P. Morozova, I. A. Nikolenko, G. V. Donchenko, S. L. Richheimer, and D. T. Bailey, "Chemiluminescence determination of the in vivo and in vitro antioxidant activity of RoseOx ${ }^{\circledR}$ and Carnosic acid," Journal of Photochemistry and Photobiology B, vol. 48, no. 1, pp. 63-67, 1999.

[15] O. I. Aruoma, B. Halliwell, R. Aeschbach, and J. Löligers, "Antioxidant and prooxidant properties of active rosemary constituents: carnosol and carnosic acid," Xenobiotica, vol. 22, no. 2, pp. 257-268, 1992.
[16] J. A. Park, S. Kim, S.-Y. Lee et al., "Beneficial effects of carnosic acid on dieldrin-induced dopaminergic neuronal cell death," Neuroreport, vol. 19, no. 13, pp. 1301-1304, 2008.

[17] K. Ninomiya, H. Matsuda, H. Shimoda et al., "Carnosic acid, a new class of lipid absorption inhibitor from sage," Bioorganic and Medicinal Chemistry Letters, vol. 14, no. 8, pp. 19431946, 2004.

[18] J. Reuter, A. Jocher, S. Hornstein, J. Mönting, and C. Schempp, "Sage extract rich in phenolic diterpenes inhibits ultravioletinduced erythema in vivo," Planta Medica, vol. 73, no. 11, pp. 1190-1191, 2007.

[19] S. Dewanjee, R. Sahu, S. Karmakar, and M. Gangopadhyay, "Toxic effects of lead exposure in Wistar rats: involvement of oxidative stress and the beneficial role of edible jute (Corchorus olitorius) leaves," Food and Chemical Toxicology, vol. 55, no. 1, pp. 78-91, 2013.

[20] Public Health Service [PHS], Public Health Service Policy on Human Care and Use of Laboratory Animals, US Department of Health and Human Services, National Institute of Health, Office of Laboratory Animal welfare, Washington, DC, 2015.

[21] S. Dewanjee, S. Joardar, N. Bhattacharjee et al., "Edible leaf extract of Ipomoea aquatica Forssk. (Convolvulaceae) attenuates doxorubicin-induced liver injury via inhibiting oxidative impairment, MAPK activation and intrinsic pathway of apoptosis," Food and Chemical Toxicology, vol. 105, pp. 322-336, 2017.

[22] P. Manna and S. K. Jain, "L-cysteine and hydrogen sulfide increase PIP3 and AMPK/PPAR $\gamma$ expression and decrease ROS and vascular inflammation markers in high glucose treated human U937 monocytes," Journal of cellular Biochemistry, vol. 114, no. 10, pp. 2334-2345, 2013.

[23] P. Manna, J. Das, J. Ghosh, and P. C. Sil, “Contribution of type 1 diabetes to rat liver dysfunction and cellular damage via activation of NOS, PARP, IkappaBalpha/NF-kappaB, MAPKs, and mitochondria-dependent pathways: prophylactic role of arjunolic acid," Free Radical Biology and Medicine, vol. 48, no. 11, pp. 1465-1484, 2010.

[24] S. Baghirova, B. G. Hughes, M. J. Hendzel, and R. Schulz, "Sequential fractionation and isolation of subcellular proteins from tissue or cultured cells," MethodsX, vol. 2, pp. 440-445, 2015.

[25] S. Dewanjee, T. K. Dua, R. Khanra et al., "Water spinach, Ipomoea aquatica (Convolvulaceae), ameliorates lead toxicity by inhibiting oxidative stress and apoptosis," PLoS One, vol. 10, no. 10, article e0139831, 2015.

[26] N. Bhattacharjee, T. K. Dua, R. Khanra et al., "Protocatechuic acid, a phenolic from Sansevieria roxburghiana leaves, suppresses diabetic cardiomyopathy via stimulating glucose metabolism, ameliorating oxidative stress, and inhibiting inflammation," Frontiers in Pharmacology, vol. 8, 2017.

[27] R. Khanra, N. Bhattacharjee, T. K. Dua et al., "Taraxerol, a pentacyclic triterpenoid, from Abroma augusta leaf attenuates diabetic nephropathy in type 2 diabetic rats," Biomedicine and Pharmacotherapy, vol. 94, pp. 726-741, 2017.

[28] D. Das, A. Chatterjee, B. K. Mandal, G. Samanta, D. Chakraborti, and B. Chanda, "Arsenic in ground water in six districts of West Bengal, India: the biggest arsenic calamity in the world. Part 2. Arsenic concentration in drinking water, hair, nails, urine, skin-scale and liver tissue (biopsy) of the affected people," Analyst, vol. 120, no. 3, pp. 917-924, 1995. 
[29] K. T. Lin, J. Y. Xue, F. F. Sun, and P. Y. K. Wong, "Reactive oxygen species participate in peroxynitrite-induced apoptosis in HL-60 Cells," Biochemical and Biophysical Research Communications, vol. 230, no. 1, pp. 115-119, 1997.

[30] A. Bolner, M. Pilleri, V. De Riva, and G. P. Nordera, "Plasma and urinary HPLC-ED determination of the ratio of 8OHdG/2-dG in Parkinson's disease," Clinical Laboratory, vol. 57, no. 11-12, pp. 859-866, 2011.

[31] N. L. Chepelev, D. A. Kennedy, R. Gagné et al., "HPLC measurement of the DNA oxidation biomarker, 8-oxo-7,8dihydro- $2^{\prime}$-deoxyguanosine, in cultured cells and animal tissues," Journal of Visualized Experiments, vol. 102, article e52697, 2015.

[32] S. Dewanjee, M. Gangopadhyay, R. Sahu, and S. Karmakar, "Cadmium induced pathophysiology: prophylactic role of edible jute (Corchorus olitorius) leaves with special emphasis on oxidative stress and mitochondrial involvement," Food and Chemical Toxicology, vol. 60, no. 1, pp. 188-198, 2013.

[33] L. Schrödinger, 2014, http://www.schrodinger.com.

[34] H. M. Berman, J. Westbrook, Z. Feng et al., "The protein data bank," Nucleic Acids Research, vol. 28, no. 1, pp. 235-242, 2000.

[35] P. Mark and L. Nilsson, "Structure and dynamics of the TIP3P, SPC, and SPC/E water models at $298 \mathrm{~K}$," Journal of Physical Chemistry A, vol. 105, no. 43, pp. 9954-9960, 2001.

[36] J.-P. Ryckaert, G. Ciccotti, and H. J. C. Berendsen, "Numerical integration of the cartesian equations of motion of a system with constraints: molecular dynamics of n-alkanes," Journal of Computational Physics, vol. 23, no. 3, pp. 327341, 1977.

[37] S. Birtić, P. Dussort, F.-X. Pierre, A. C. Bily, and M. Roller, "Carnosic acid," Phytochemistry, vol. 115, pp. 9-19, 2015.

[38] F. Aguilar, H. Autrup, S. Barlow et al., "Use of rosemary extracts as a food additive-scientific opinion of the panel on food additives, flavourings, processing aids and materials in contact with food," The EFSA Journal, vol. 721, no. 1, pp. 1-29, 2008.

[39] L. Demetrius, "Of mice and men," EMBO Reports, vol. 6, pp. S39-S44, 2005.

[40] M. Vahter and G. Concha, "Role of metabolism in arsenic toxicity," Pharmacology \& Toxicology, vol. 89, no. 1, pp. 1-5, 2001.

[41] J. C. States, A. Barchowsky, I. L. Cartwright, J. F. Reichard, B. W. Futscher, and R. C. Lantz, "Arsenic toxicology: translating between experimental models and human pathology," Environmental Health Perspectives, vol. 119, no. 10, pp. 1356-1363, 2011.

[42] N. C. Sumedha and S. Miltonprabu, "Arsenic induced oxidative hematotoxicity in rats and its protection by diallyl trisulfide," International Journal of Biological and Pharmaceutical Research, vol. 4, no. 7, pp. 507-515, 2013.

[43] Z. Zhang, P. Pratheeshkumar, A. Budhraja, Y.-O. Son, D. Kim, and X. Shi, "Role of reactive oxygen species in arsenic-induced transformation of human lung bronchial epithelial (BEAS-2B) cells," Biochemical and Biophysical Research Communications, vol. 456, no. 2, pp. 643-648, 2015.

[44] S. Dewanjee, A. K. Das, R. Sahu, and M. Gangopadhyay, "Antidiabetic activity of Diospyros peregrina fruit: effect on hyperglycemia, hyperlipidemia and augmented oxidative stress in experimental type 2 diabetes," Food and Chemical Toxicology, vol. 47, no. 10, pp. 2679-2685, 2009.

[45] A. J. Searle and R. L. Willson, "Glutathione peroxidase: effect of superoxide, hydroxyl and bromine free radicals on enzyme activity," International Journal of Radiation Biology and Related Studies in Physics, Chemistry and Medicine, vol. 37, no. 2, pp. 213-217, 1980.

[46] S. Shen, X.-F. Li, W. R. Cullen, M. Weinfeld, and X. C. Le, "Arsenic binding to proteins," Chemical Reviews, vol. 113, no. 10, pp. 7769-7792, 2013.

[47] H. V. Aposhian, "Enzymatic methylation of arsenic species and other new approaches to arsenic toxicity," Annual Review of Pharmacology and Toxicology, vol. 37, no. 1, pp. 397-419, 1997.

[48] E. M. Leslie, A. Haimeur, and M. P. Waalkes, “Arsenic transport by the human multidrug resistance protein 1 (MRP1/ $\mathrm{ABCC} 1$ ) evidence that a tri-glutathione conjugate is required," Journal of Biological Chemistry, vol. 279, no. 31, pp. 3270032708, 2004.

[49] B. D. Sahu, K. K. R. Rentam, U. K. Putcha, M. Kuncha, G. M. N. Vegi, and R. Sistla, "Carnosic acid attenuates renal injury in an experimental model of rat cisplatin-induced nephrotoxicity," Food and Chemical Toxicology, vol. 49, no. 12, pp. 3090-3097, 2011.

[50] O. O. Odunuga, G. W. Okunade, and O. O. Olorunsogo, "Reversal of sodium arsenite inhibition of rat liver microsomal $\mathrm{Ca}^{2+}$ pumping ATPase by vitamin C," Bioscience Reports, vol. 19, no. 1, pp. 11-15, 1999.

[51] T. Satoh, M. Izumi, Y. Inukai et al., "Carnosic acid protects neuronal HT22 Cells through activation of the antioxidantresponsive element in free carboxylic acid- and catechol hydroxyl moieties-dependent manners," Neuroscience Letters, vol. 434, no. 3, pp. 260-265, 2008.

[52] J. Cai, J. Yang, and D. P. Jones, "Mitochondrial control of apoptosis: the role of cytochrome c," Biochimica et Biophysica Acta (BBA) - Bioenergetics, vol. 1366, no. 1-2, pp. 139-149, 1998.

[53] G. W. Wang, J. B. Klein, and Y. J. Kang, "Metallothionein inhibits doxorubicin induced mitochondrial cytochrome $c$ release and caspase-3 activation in cardiomyocytes," Journal of Pharmacology and Experimental Therapeutics, vol. 298, no. 2, pp. 461-468, 2001.

[54] M. L. Circu and T. Y. Aw, "Reactive oxygen species, cellular redox systems and apoptosis," Free Radical Biology and Medicine, vol. 48, no. 6, pp. 749-762, 2010.

[55] P. E. Czabotar, G. Lessene, A. Strasser, and J. M. Adams, "Control of apoptosis by the BCL-2 protein family: implications for physiology and therapy," Nature Reviews Molecular Cell Biology, vol. 15, no. 1, pp. 49-63, 2014.

[56] M. J. Morgan and Z.-G. Liu, "Crosstalk of reactive oxygen species and NF- $\kappa \mathrm{B}$ signaling," Cell Research, vol. 21, no. 1, pp. 103-115, 2011.

[57] M. Barkett and T. D. Gilmore, "Control of apoptosis by Rel/NF-kB transcription factors," Oncogene, vol. 18, no. 49, pp. 6910-6924, 1999.

[58] T. Wada and J. M. Penninger, "Mitogen activated protein kinases in apoptosis regulation," Oncogene, vol. 23, no. 16, pp. 2838-2849, 2004.

[59] G. S. Wu, "The functional interactions between the MAPK and p53 signaling pathways," Cancer Biology \& Therapy, vol. 3, no. 2, pp. 156-161, 2014. 
[60] N. Bhattacharjee, S. Barma, N. Konwar, S. Dewanjee, and P. Manna, "Mechanistic insight of diabetic nephropathy and its pharmacotherapeutic targets: an update," European Journal of Pharmacology, vol. 791, no. 1, pp. 8-24, 2016.

[61] A. Yoda, K. Toyoshima, Y. Watanabe et al., "Arsenic trioxide augments Chk2/p53-mediated apoptosis by inhibiting oncogenic Wip1 phosphatase," Journal of Biological Chemistry, vol. 283, no. 27, pp. 18969-18979, 2008. 


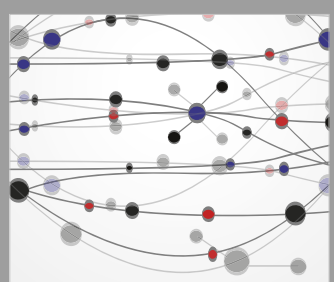

The Scientific World Journal
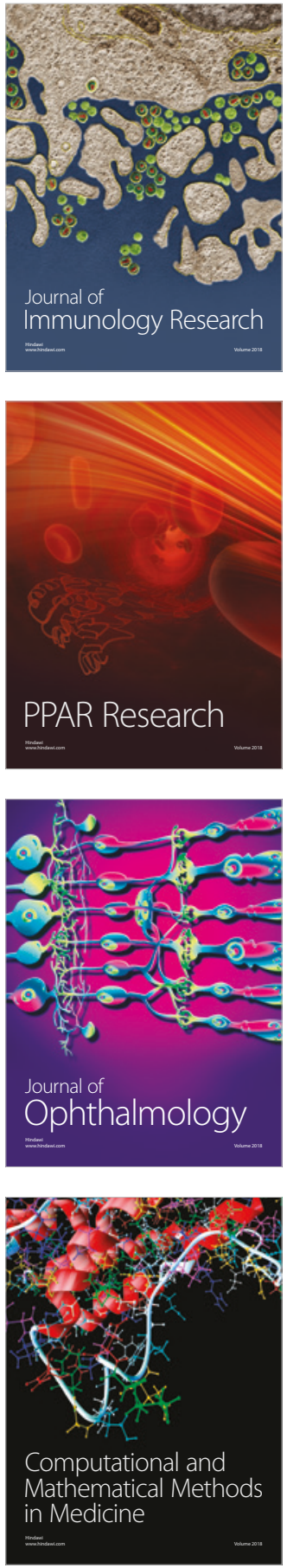

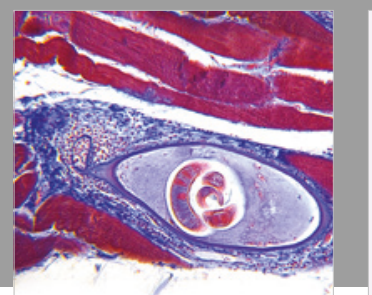

Gastroenterology Research and Practice

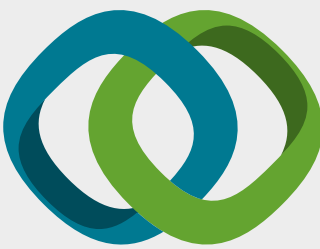

\section{Hindawi}

Submit your manuscripts at

www.hindawi.com
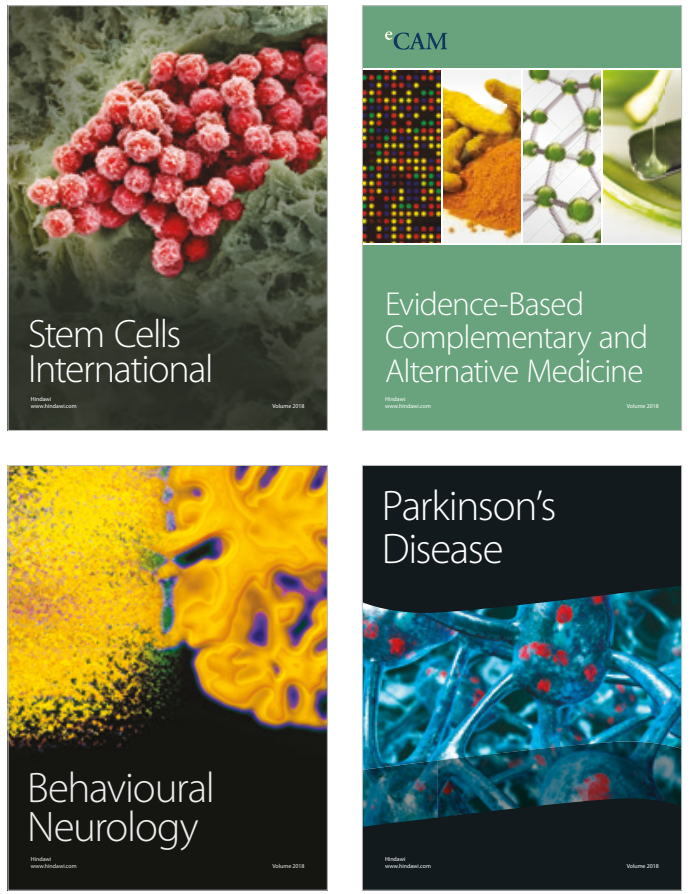

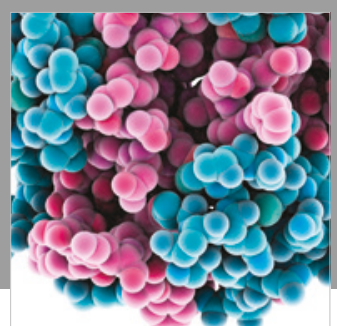

ournal of

Diabetes Research

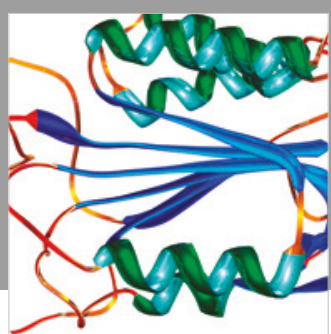

Disease Markers
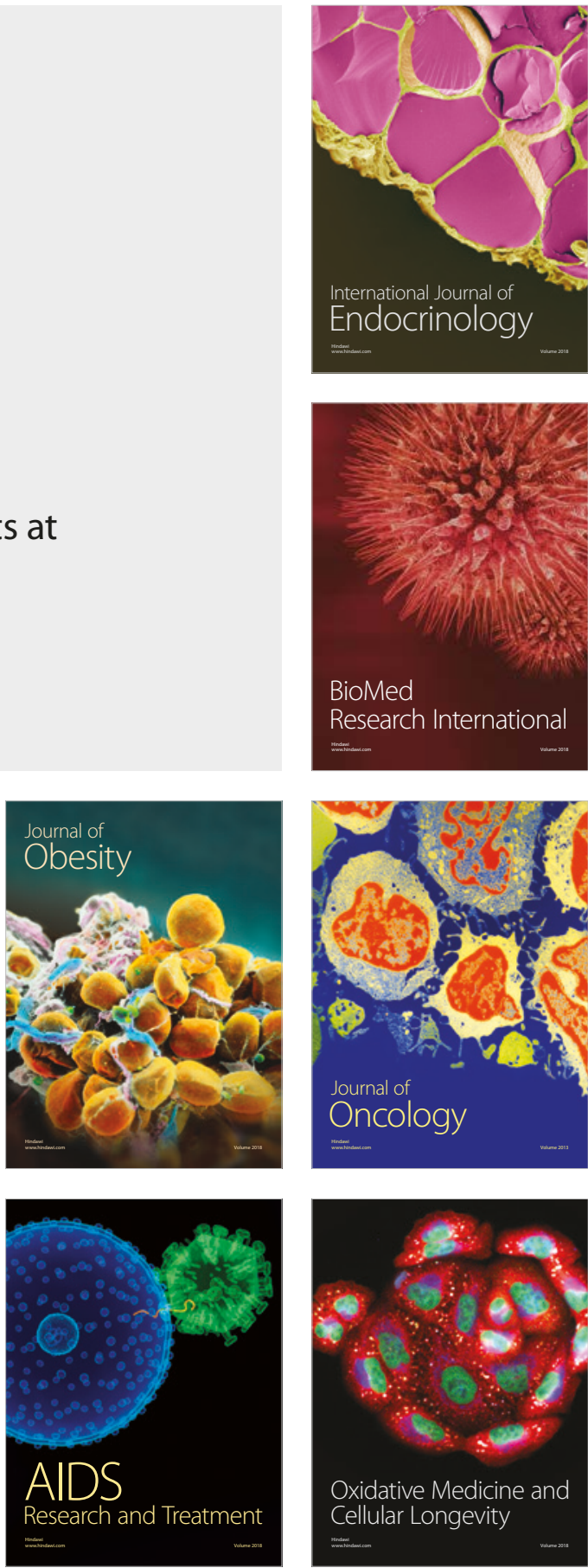